Article

\title{
Augmenting the Activity of Monoterpenoid Phenols against Fungal Pathogens Using 2-Hydroxy-4-methoxybenzaldehyde that Target Cell Wall Integrity
}

\author{
Jong H. Kim *, Kathleen L. Chan and Noreen Mahoney \\ Received: 19 September 2015 ; Accepted: 2 November 2015 ; Published: 10 November 2015 \\ Academic Editor: Paula Andrade \\ Foodborne Toxin Detection and Prevention Research Unit, Western Regional Research Center, \\ Agricultural Research Service, United States Department of Agriculture, Albany, CA 94710, USA; \\ kathy.chan@ars.usda.gov (K.L.C.); noreen.mahoney@ars.usda.gov (N.M.) \\ * Correspondence: jongheon.kim@ars.usda.gov; Tel.: +1-510-559-5841; Fax: +1-510-559-6429
}

\begin{abstract}
Disruption of cell wall integrity system should be an effective strategy for control of fungal pathogens. To augment the cell wall disruption efficacy of monoterpenoid phenols (carvacrol, thymol), antimycotic potency of benzaldehyde derivatives that can serve as chemosensitizing agents were evaluated against strains of Saccharomyces cerevisiae wild type (WT), slt2 $\Delta$ and bck1 1 (mutants of the mitogen-activated protein kinase (MAPK) and MAPK kinase kinase, respectively, in the cell wall integrity pathway). Among fourteen compounds investigated, slt $2 \Delta$ and $b c k 1 \Delta$ showed higher susceptibility to nine benzaldehydes, compared to WT. Differential antimycotic activity of screened compounds indicated "structure-activity relationship" for targeting the cell wall integrity, where 2-hydroxy-4-methoxybenzaldehyde (2H4M) exhibited the highest antimycotic potency. The efficacy of $2 \mathrm{H} 4 \mathrm{M}$ as an effective chemosensitizer to monoterpenoid phenols (viz., $2 \mathrm{H} 4 \mathrm{M}+$ carvacrol or thymol) was assessed in yeasts or filamentous fungi (Aspergillus, Penicillium) according to European Committee on Antimicrobial Susceptibility Testing or Clinical Laboratory Standards Institute M38-A protocols, respectively. Synergistic chemosensitization greatly lowers minimum inhibitory or fungicidal concentrations of the co-administered compounds. $2 \mathrm{H} 4 \mathrm{M}$ also overcame

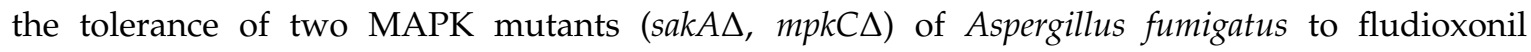
(phenylpyrrole fungicide). Collectively, $2 \mathrm{H} 4 \mathrm{M}$ possesses chemosensitizing capability to magnify the efficacy of monoterpenoid phenols, which improves target-based (viz., cell wall disruption) antifungal intervention.
\end{abstract}

Keywords: antimycotic; benzaldehydes; cell wall integrity; chemosensitization; filamentous fungi; monoterpenoids; mycotoxins; Saccharomyces cerevisiae; signal transduction; synergism

\section{Introduction}

Filamentous fungi in the genus Aspergillus are ubiquitous opportunistic pathogens, which are most notable as causative agents of highly enervating human diseases such as aspergillosis [1]. They form extremely invasive human infections, particularly in immunocompromised patients or in people suffering chronic granulomatosis [2-4]. Aspergillus flavus and Aspergillus parasiticus also produce highly (hepato)carcinogenic aflatoxins, which contaminate various agricultural/food commodities [5]. Filamentous fungi in the genus Penicillium also frequently cause food contamination or postharvest decay, where P. expansum is the main producer of the mycotoxin patulin that negatively affects human and animal health [6]. 
Mycotic diseases/infections are becoming a serious problem since effective antifungal drugs or fungicides, especially agents for treating drug/fungicide-resistant fungi, are very limited. Development of fungal resistance to conventional antimycotic agents not only triggers global public health issues, but also threatens the safety of food supplies, especially for the products susceptible to mycotoxin contamination $[7,8]$. For instance, continuous applications of widely used fungicides, such as strobilurins, fludioxonils, etc., to agricultural fields resulted in the development of fungal resistance to (and thus, escape from) the toxicities of fungicides. Moreover, applying fungicides at suboptimal concentrations or time-points of fungal growth can potentiate toxin production by mycotoxigenic fungi $[9,10]$. Fungicide-potentiation of mycotoxin production in fungi, especially those resistant to fungicides, has been reported in various aflatoxin-, trichothecene-, citrinin-, and patulin-producing fungal pathogens (See Table 1). Accordingly, there is an urgent demand to increase the efficacy of conventional antimycotic drugs/fungicides or develop new intervention strategies, which can secure the safe production of crops and food as well as public health.

Table 1. Fungicide potentiation of mycotoxin production in fungal pathogens.

\begin{tabular}{|c|c|c|}
\hline Fungi & Fungicide & Key Features (Potentiation of Mycotoxin Production) \\
\hline Aspergillus parasiticus & Anilinopyrimidine & $\begin{array}{l}\text { Correlation between fitness parameters and } \\
\text { aflatoxigenicity [11] }\end{array}$ \\
\hline A. parasiticus & Flusilazole & $\begin{array}{l}\text { Highly aflatoxigenic, sterol demethylation } \\
\text { inhibition-resistant isolates [12] }\end{array}$ \\
\hline A. parasiticus & Phenylpyrrole & $\begin{array}{l}\text { Highly aflatoxigenic, phenylpyrrole resistant } \\
\text { isolates [13] }\end{array}$ \\
\hline Fusarium graminearum & Carbendazim & $\begin{array}{l}\text { Increased trichothecene production with carbendazim } \\
\text { resistance [14] }\end{array}$ \\
\hline Fusarium sp. & Strobilurins & $\begin{array}{c}\text { Increased deoxynivalenol production by sub-optimal } \\
\text { application of strobilurin [9] }\end{array}$ \\
\hline F. sporotrichioides & Carbendazim & $\begin{array}{l}\text { Higher mycotoxin production (T-2 toxin, } \\
\text { 4,15-diacetoxyscirpenol, neosolaniol) with } \\
\text { carbendazim resistance [15] }\end{array}$ \\
\hline Penicillium expansum & $\begin{array}{l}\text { Tebuconazole, } \\
\text { Fludioxonil, etc. }\end{array}$ & $\begin{array}{l}\text { Adverse effect of fitness penalties on the } \\
\text { mycotoxigenicity of resistant isolates [16] }\end{array}$ \\
\hline P. expansum & Benzimidazole & $\begin{array}{l}\text { Highly mycotoxigenic field isolates resistant to the } \\
\text { benzimidazoles [17] }\end{array}$ \\
\hline P. verrucosum & Iprodione & $\begin{array}{c}\text { Strong induction of mycotoxin biosynthesis by } \\
\text { iprodione [18] }\end{array}$ \\
\hline
\end{tabular}

The cell wall integrity system of fungi is an effective target for control of fungal pathogens [19]. The cell wall integrity pathway is well elucidated and described in the model fungus Saccharomyces cerevisiae, where the operation of mitogen-activated protein kinase (MAPK) signaling pathway (viz., cell wall integrity pathway) is controlled by protein kinase C [20]. The BCK1 and SLT2 genes, which encode MAPK kinase kinase (MAPKKK) and MAPK, respectively (Table 2), in the pathway play crucial roles for maintaining cell wall integrity in fungi [20]. Studies have shown that genes in the cell wall integrity system in fungi, such as species in the genus Aspergillus and S. cerevisiae, are functionally well conserved [21,22]. Therefore, cell wall targeting drugs (e.g., echinocandins) could be administered as broad-spectrum antimycotic agents for control of filamentous or yeast fungal pathogens, including species of Candida ([23] and references therein).

Nevertheless, despite their usefulness as cell wall targeting drugs, echinocandins generally do not completely inhibit fungal growth ([24] and references therein), where the determination of precise endpoints for pathogen intervention is very rigorous [25]. Echinocandin treatment can also trigger a compensatory stimulation of chitin synthesis, which causes the development of fungal resistance 
to the drugs ([24] and references therein). Accordingly, development of new drugs or intervention strategies is continually required for effective control of fungal pathogens, especially the strains exhibiting drug or fungicide resistance.

Table 2. Microbial strains used in this study.

\begin{tabular}{|c|c|c|}
\hline Aspergillus & Characteristics & Source/References \\
\hline A. flavus 3357 & $\begin{array}{l}\text { Plant pathogen (aflatoxin), Human pathogen } \\
\text { (aspergillosis), Reference aflatoxigenic strain used for } \\
\text { genome sequencing }\end{array}$ & NRRL $^{a}[26]$ \\
\hline A. flavus 4212 & $\begin{array}{l}\text { Plant pathogen (aflatoxin), Human } \\
\text { pathogen (aspergillosis) }\end{array}$ & NRRL \\
\hline A. parasiticus 5862 & Plant pathogen (aflatoxin) & NRRL \\
\hline A. parasiticus 2999 & Plant pathogen (aflatoxin) & NRRL \\
\hline A. fumigatus AF293 & $\begin{array}{l}\text { Human pathogen (aspergillosis), Parental strain, } \\
\text { Reference clinical strain used for genome sequencing }\end{array}$ & {$[26,27]$} \\
\hline A. fumigatus sakA $\Delta$ & $\begin{array}{l}\text { Human pathogen (aspergillosis), Mitogen-Activated } \\
\text { Protein Kinase (MAPK) gene deletion mutant derived } \\
\text { from AF293 }\end{array}$ & [27] \\
\hline A. fumigatus mpkC $\Delta$ & $\begin{array}{c}\text { Human pathogen (aspergillosis), Mitogen-Activated } \\
\text { Protein Kinase (MAPK) gene deletion mutant derived } \\
\text { from AF293 }\end{array}$ & {$[28]$} \\
\hline P. expansum $\mathrm{W} 1$ & Plant pathogen (patulin), Parental strain & [29] \\
\hline P. expansum FR2 & $\begin{array}{l}\text { Plant pathogen (patulin), Fludioxonil resistant mutant } \\
\text { derived from P. expansum W1 }\end{array}$ & [29] \\
\hline P. expansum $\mathrm{W} 2$ & Plant pathogen (patulin), Parental strain & [29] \\
\hline P. expansum FR3 & $\begin{array}{l}\text { Plant pathogen (patulin), Fludioxonil resistant mutant } \\
\text { derived from P. expansum W2 }\end{array}$ & [29] \\
\hline Saccharomyces & Characteristics & Source/References \\
\hline S. cerevisiae BY4741 & $\begin{array}{l}\text { Model yeast, Parental strain (Mat a his } 3 \Delta 1 \text { leu } 2 \Delta 0 \\
\text { met } 15 \Delta 0 \text { ura } 3 \Delta 0)\end{array}$ & {$[30]$} \\
\hline S. cerevisiae slt $2 \Delta$ & $\begin{array}{l}\text { MAPK mutant in cell wall integrity system derived } \\
\text { from BY4741 }\end{array}$ & [30] \\
\hline S. cerevisiae bck1 $1 \Delta$ & $\begin{array}{l}\text { MAPK kinase kinase (MAPKKK) mutant derived } \\
\text { from BY4741 }\end{array}$ & {$[30]$} \\
\hline
\end{tabular}

${ }^{a}$ NRRL, National Center for Agricultural Utilization Research, USDA-ARS, Peoria, IL, USA.

Antifungal chemosensitization is an intervention scheme for effective control of pathogenic fungi, where co-application of a selected natural or synthetic compound (viz., a chemosensitizer or a chemosensitizing agent) with a conventional antifungal drug can intensify the drug efficacy [31]. Chemosensitization strategy makes the fungal pathogens highly susceptible to the drug co-administered, where the chemosensitizer significantly impaired fungal defense to the conventional drug. By definition, comparing to the traditional combination therapy (viz., combined application of two or more commercial drugs), a chemosensitizer itself does not have to exhibit a high extent of antifungal potency. However, chemosensitization not only magnifies the efficacy of the antimycotic drug co-applied, but also overcomes pathogen resistance to conventional drugs [31]. For example, co-application of piperazinyl quinolone with the azole drug fluconazole (FLC) resulted in overcoming FLC resistance of $C$. albicans, while the compound showed no antimycotic activity when applied alone [32]. Also, co-administration of cyclobutene-dione (squarile) derivatives with FLC elevated the drug activity during the treatment of $C$. albicans, where the chemosensitizer(s) modulated the major facilitator superfamily transporter (Mdr1p; responsible for FLC resistance) of the pathogen [33]. 
Chemosensitization mediated by a D-octapeptide derivative further overcame FLC resistance in S. cerevisiae and pathogenic fungi [34]. Collectively, fungal intervention via chemosensitization could be an alternative to (or complement) current antifungal practices, for example, combination therapy.

Natural products that present no significant medical or environmental side effects are potential sources of antimycotic or antimycotoxigenic agents, either in their nascent structure or as leads for more potent derivatives [35]. For instance, benzo derivatives (such as vanillic or caffeic acid) not only inhibited the growth of filamentous fungal pathogens, but also disrupted the production of mycotoxins [36]. The redox-active natural products, such as phenolic agents, can be potent redox cyclers that prevent fungal growth by interfering cellular redox homeostasis (thus, triggering fungal oxidative stress) or by disrupting the integrity of cellular components [37,38]. For defense, the fungal antioxidant system or cell wall/membrane integrity system play important roles for fungal tolerance to the phenolic agents administered [37,38].

Terpenoid phenols, such as carvacrol (5-isopropyl-2-methylphenol) and its structural isomer thymol (2-isopropyl-5-methylphenol) (Figure 1), have been demonstrated to be effective natural antimycotic agents by inhibiting the growth or activity of planktonic or biofilms of fungal pathogens ([39] and references therein). Carvacrol and thymol are generally regarded as safe (GRAS) reagents [40], and thus, are currently used as food additives. Genome-wide transcription profiling (microarray) study in the model fungus S. cerevisiae disclosed that genes in metabolic (energy, pyrimidine), biosynthetic, stress responses (oxidative, heat shock), etc., were highly up- or down-regulated with the treatment of carvacrol, where the ion homeostasis mutant $(v m a \Delta)$ was also hypersensitive to carvacrol treatment [39]. Similar microarray analysis in S. cerevisiae treated with thymol also revealed that genes involved in metabolism (sulfur, protein, thiamin, nucleic acid, etc.), mitochondrial function, organellar ribosome, cell proliferation, etc., were up- or down-regulated by thymol application [41]. However, effects of carvacrol or thymol on the function of cell wall integrity system were undetermined in these studies.
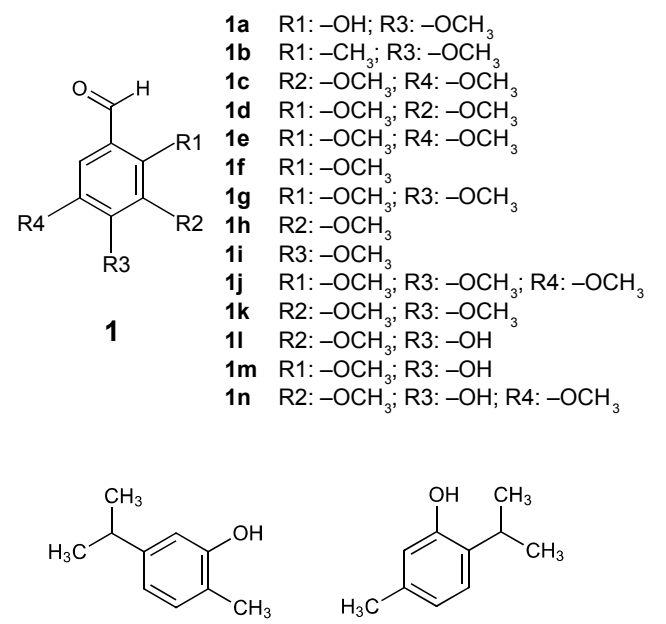

2

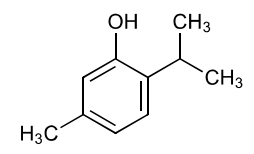

3

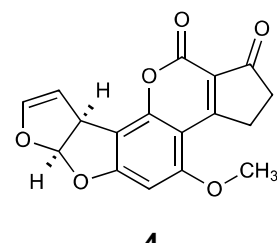

4

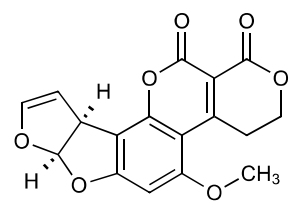

6

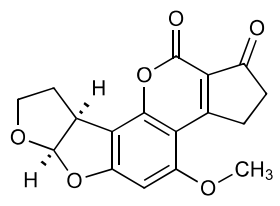

5

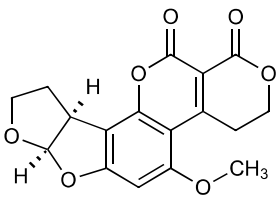

7

Figure 1. Structures of benzo derivatives, carvacrol, thymol, and aflatoxins used/detected in this study. (1) Benzaldehyde and derivatives: (1a) 2-Hydroxy-4-methoxybenzaldehyde, (1b) 2-Methyl-4methoxybenzaldehyde, (1c) 3,5-Dimethoxybenzaldehyde, (1d) 2,3-Dimethoxybenzaldehyde, (1e) 2,5-Dimethoxybenzaldehyde, (1f) 2-Methoxybenzaldehyde, (1g) 2,4-Dimethoxybenzaldehyde, (1h) 3-Methoxybenzaldehyde, (1i) 4-Methoxybenzaldehyde, (1j) 2,4,5-Trimethoxybenzaldehyde, (1k) 3,4-Dimethoxybenzaldehyde, (11) 4-Hydroxy-3-methoxybenzaldehyde, (1m) 4-Hydroxy-2methoxybenzaldehyde, (1n) 3,5-Dimethoxy-4-hydroxybenzaldehyde; (2) Carvacrol (5-Isopropyl-2methylphenol); (3) Thymol (2-Isopropyl-5-methylphenol); (4) Aflatoxin $\mathrm{B}_{1}$; (5) Aflatoxin $\mathrm{B}_{2}$; (6) Aflatoxin $\mathrm{G}_{1}$; (7) Aflatoxin $\mathrm{G}_{2}$. 
The benzo derivative 2-hydroxy-4-methoxybenzaldehyde (2H4M) (Figure 1) is also a GRAS reagent [40], and hence, is currently used as a food additive. The 2H4M has been isolated from different plants as a natural compound, where it functioned as an insect repellent to protect food sources, etc. [42,43]. In this study, two $S$. cerevisiae cell wall integrity mutants (bck1 $\Delta$, slt2 $\Delta)$, where genes in cell wall integrity MAPK pathway were deleted (Table 2), were examined to evaluate the efficacy of targeting cell wall integrity via natural product-based antifungal chemosensitization (namely, monoterpenoid phenols $+2 \mathrm{H} 4 \mathrm{M}$ ). The same intervention strategy was also investigated in filamentous fungal pathogens, such as Aspergillus and Penicillium, according to the Clinical Laboratory Standards Institute (CLSI) M38-A [44]. Results showed that: (1) 2H4M functioned as an effective antifungal chemosensitizer to augment the potency of monoterpenoid phenols; and (2) $2 \mathrm{H} 4 \mathrm{M}$ overcame the tolerance of $A$. fumigatus MAPK mutants $(\operatorname{sak} A \Delta, m p k C \Delta$ ) to fludioxonil, a phenylpyrrole fungicide.

\section{Results and Discussion}

\subsection{Identification of 2-Hydroxy-4-methoxybenzaldehyde (2H4M) as the Most Potent Antifungal Benzaldehyde Analog via Yeast Screening: Structure-Activity Relationship}

Antifungal efficacy of fourteen analogs of benzaldehyde (BA; basic structure) was investigated against the wild type (WT) and two cell wall integrity mutants $(b c k 1 \Delta$, slt $2 \Delta)$ of $S$. cerevisiae, in in vitro agar plate (yeast dilution) bioassays. The $b c k 1 \Delta$ and $s l t 2 \Delta$ previously showed hypersensitivity to cell wall perturbing agents, such as caspofungin [45], and hence, can serve as screening tools for identifying new cell wall disrupting agents. Firstly, $2 \mathrm{H} 4 \mathrm{M}$ was found to possess the highest antifungal activity against $S$. cervisiae strains (viz., no growth of $b c k 1 \Delta$, slt $2 \Delta$ and WT at $5.0 \mathrm{mM}$ cutoff) (Table 3). Test benzaldehydes were further classified into three groups based on the level of antifungal potency against $b c k 1 \Delta$ and slt2 $\Delta$ mutants as follows: Group 1, 2H4M, 2-methyl-4-methoxybenzaldehyde, 3,5-dimethoxybenzaldehyde (3,5-DMBA), 2,3-dimethoxybenzaldehyde (2,3-DMBA) (Complete growth inhibition of $b c k 1 \Delta$ and slt2 $\Delta$ mutants at $5.0 \mathrm{mM}$ cutoff (viz., growth score $=0$; See Experimental section)); Group 2, 2,5-dimethoxybenzaldehyde (2,5-DMBA), 2-methoxybenzaldehyde, 2,4-dimethoxybenzaldehyde (2,4-DMBA), 3-methoxybenzaldehyde, 4-methoxybenzaldehyde [Moderate growth inhibition of bck1 $\Delta$ and slt $2 \Delta$ mutants at $5.0 \mathrm{mM}$ cutoff (viz., growth score $=1$ to 4)]; and Group 3, 2,4,5-trimethoxybenzaldehyde, 3,4-dimethoxybenzaldehyde (3,4-DMBA), 4-hydroxy-3-methoxybenzaldehyde, 4-hydroxy-2-methoxybenzaldehyde (4H2M), 3,5-dimethoxy-4-hydroxybenzaldehyde, BA (No growth inhibition of bck1 $\Delta$ and slt2 $\Delta$ mutants at $5.0 \mathrm{mM}$ cutoff (viz., growth score $=6)$ ) (Table 3).

Table 3. Growth scores of yeasts at $5 \mathrm{mM}$ (cutoff) of benzaldehyde derivatives during yeast dilution bioassay (0, No growth; 6, Full growth; See Experimental section).

\begin{tabular}{cccc}
\hline Benzaldehyde Derivatives & WT & slt2 $\Delta$ & bck1 $\Delta$ \\
\hline 2-Hydroxy-4-methoxybenzaldehyde & 0 & 0 & 0 \\
2-Methyl-4-methoxybenzaldehyde & 1 & 0 & 0 \\
3,5-Dimethoxybenzaldehyde & 1 & 0 & 0 \\
2,3-Dimethoxybenzaldehyde & 2 & 0 & 0 \\
2,5-Dimethoxybenzaldehyde & 2 & 1 & 1 \\
2-Methoxybenzaldehyde & 3 & 1 & 1 \\
2,4-Dimethoxybenzaldehyde & 4 & 3 & 3 \\
3-Methoxybenzaldehyde & 6 & 3 & 2 \\
4-Methoxybenzaldehyde & 6 & 4 & 4 \\
2,4,5-Trimethoxybenzaldehyde & 6 & 6 & 6 \\
3,4-Dimethoxybenzaldehyde & 6 & 6 & 6 \\
4-Hydroxy-3-methoxybenzaldehyde & 6 & 6 & 6 \\
4-Hydroxy-2-methoxybenzaldehyde & 6 & 6 & 6 \\
3,5-Dimethoxy-4-hydroxybenzaldehyde & 6 & 6 & 6 \\
Benzaldehyde & 6 & 6 & 6 \\
\hline
\end{tabular}


Structure-activity relationships were also found with the test compounds. Structural-activity relationship in this study is defined as the relationship between the structures of test compounds (benzaldehydes), i.e., kinds of chemical groups/side chains and/or their position on the benzene ring, and the level of antifungal activity. For example, the growth of $S$. cerevisiae bck1 $\Delta$ and slt2 $\Delta$ (and WT) was almost not affected by 3,4-DMBA (growth score =6), while that of test strains treated with 3,5-DMBA (having a shift of a methoxyl residue from \#4 to \#5 position on the benzene ring) was greatly disrupted, where the level of growth inhibition was commensurate with compound concentration (1.0 to $5.0 \mathrm{mM}$ ) (viz., growth score $=0$ to 5) (Figure 2; Table 3). Of note is that, while $2 \mathrm{H} 4 \mathrm{M}$ was the most potent antifungal compound tested against WT, $b c k 1 \Delta$ and slt $2 \Delta$ (growth score $=0$ at $5.0 \mathrm{mM}$ cutoff; Table 3), the $4 \mathrm{H} 2 \mathrm{M}$, where the hydroxyl- and methoxyl-residues were reciprocally exchanged compared to $2 \mathrm{H} 4 \mathrm{M}$, exhibited almost no antimycotic activity in the same yeast strains (growth score $=6$ at $5.0 \mathrm{mM}$ cutoff; Table 3). Besides, the 2,3- and 2,5-DMBA exhibited higher antifungal potency (against the $b c k 1 \Delta$ and slt2 $\Delta$ ) compared to 2,4-DMBA [order of activity (high to low): 2,3-DMBA (growth score $=0$ ) $>2,5$-DMBA (growth score $=1$ ) $>2,4$-DMBA (growth score =6)]. Similar characteristics could be found in a prior study with quinone derivatives, where activities or functions of enzymes or cellular proteins were disrupted mainly by those analogs possessing an orthoor para-quinonoid structure [46].

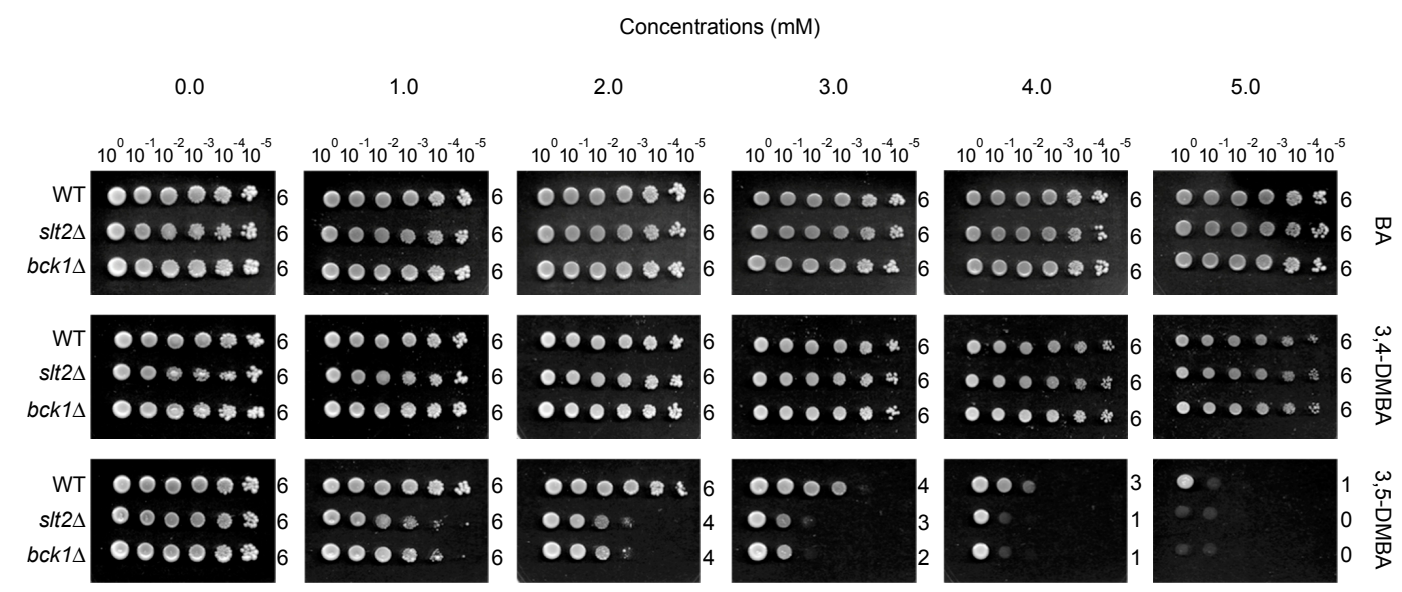

Figure 2. Differential susceptibility of $S$. cerevisiae strains to benzaldehyde derivatives. Exemplary yeast dilution bioassay showed that $S$. cerevisiae cell wall integrity mutants $(s l t 2 \Delta, b c k 1 \Delta)$ were more susceptible to 3,5-DMBA compared to WT. Results also showed the structure-activity relationship, where 3,5-DMBA possessed potent antifungal activity (at 1 to $5 \mathrm{mM}$ ), while BA and 3,4-DMBA exhibited no antimycotic potency at the same concentrations. Numbers on right side of each row (0 to 6) indicate growth scores (See Experimental section).

Collectively, nine out of fifteen benzaldehydes (including $\mathrm{BA}$ as the basic structure) negatively affected the growth of $b c k 1 \Delta$ and $\operatorname{slt} 2 \Delta$, the cell wall integrity mutants of $S$. cerevisiae, with structure-activity relationship. $2 \mathrm{H} 4 \mathrm{M}$ possessed the highest antifungal activity among test compounds.

\subsection{Growth Recovery of S. cerevisiae bck1 $\Delta$ and slt2 $\Delta$ Mutants by Sorbitol}

In sorbitol remediation bioassay, sensitivity of slt2 $\Delta$ and $b c k 1 \Delta$ to carvacrol, thymol, $2 \mathrm{H} 4 \mathrm{M}$ or 2,3-DMBA was alleviated by sorbitol (caffeine: positive control for cell wall perturbation) (See Experimental section and [47] for method). The level of growth of $s l t 2 \Delta$ and $b c k 1 \Delta$ on sorbitol-containing media was 10 to 100 times higher compared to controls without sorbitol (Figure 3 ). Therefore, the remediation by sorbitol indicates that disruption of cell wall integrity in fungi is one contributing mechanism of how the screened benzaldehydes (including thymol and carvacrol) exerted antimycotic activity (alone or in combination with monoterpenoid phenols; See below). 


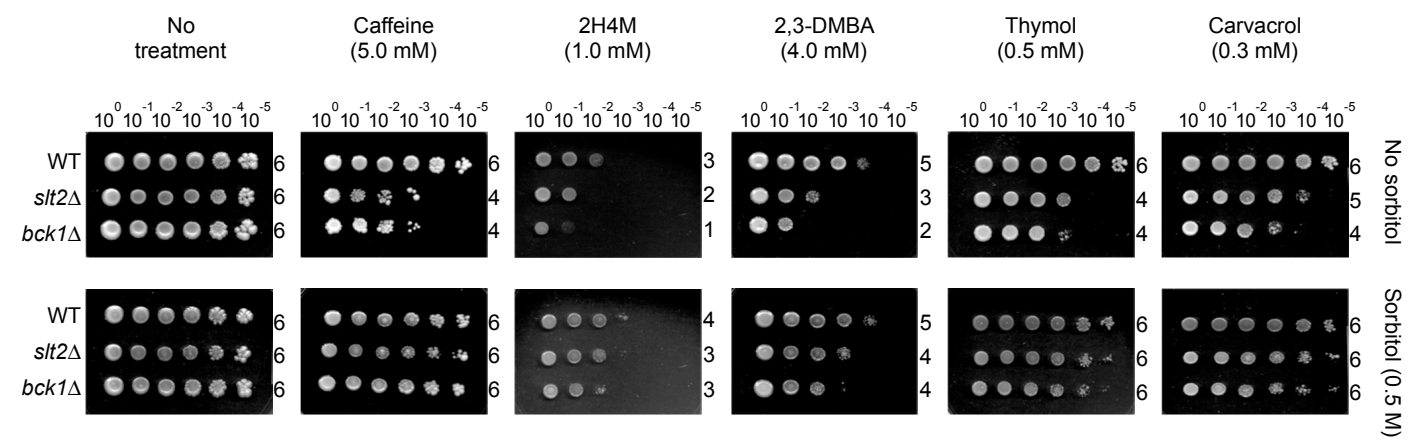

Figure 3. Yeast dilution bioassay showing sensitivity of $S$. cerevisiae slt $2 \Delta$ and $b c k 1 \Delta$ mutants to caffeine (5 mM; control) and test compounds (2H4M, 2,3-DMBA, thymol, carvacrol) was remediated by sorbitol. Results indicate the test compounds negatively affected cell wall integrity system of fungi.

\subsection{Chemosensitization Test in S. cerevisiae: Co-Application of Thymol or Carvacrol with 2H4M Augmented} the Antifungal Efficacy of Test Compounds in S. cerevisiae

Antifungal chemosensitization was examined based on European Committee on Antimicrobial Susceptibility Testing (EUCAST) broth dilution protocol for yeasts [48], where both minimum inhibitory concentrations (MICs) and minimum fungicidal concentrations (MFCs), and thus, their respective Fractional Inhibitory Concentration Indices (FICI) and Fractional Fungicidal Concentration Indices (FFCI), of S. cerevisiae WT, slt2 $\Delta$ and $b c k 1 \Delta$ were calculated (See Experimental section for calculations and concentrations of test compounds).

For FFCIs of carvacrol, "synergistic" FFCIs (i.e., FFCI $\leqslant 0.5$ ) were not identified between $2 \mathrm{H} 4 \mathrm{M}$ and carvacrol for the test strains (Table 4). However, despite the absence of calculated synergism (as determined by "indifferent" interactions [49]) (Table 4), there was increased antifungal activity of $2 \mathrm{H} 4 \mathrm{M}$ and carvacrol (viz., chemosensitizing effect; FFCIs $=0.6$ to 0.8 ) in WT, slt2 $\Delta$ and $b c k 1 \Delta$, which was reflected in lowered MFCs of test compounds when they were co-applied. For example, co-application of $2 \mathrm{H} 4 \mathrm{M}(3.2,1.6$ or $1.6 \mathrm{mM}$ for WT, slt2 $\Delta$ and $b c k 1 \Delta$, respectively) with carvacrol (3.2 $\mathrm{mM}$ for all strains) completely prevented the yeast growth (on recovery agar plate), while individual treatment of each compound, alone, at the same dosages allowed the survival of yeast strains (See also Figure 4). Noteworthy is that slt2 2 (MAPK) and bck1 $($ MAPKKK) required much lower concentration of $2 \mathrm{H} 4 \mathrm{M}(1.6 \mathrm{mM})$ compared to WT $(3.2 \mathrm{mM})$ to achieve complete inhibition of yeast growth, thus demonstrating that the knockout strains are less capable of responding to the cell wall perturbation induced by $2 \mathrm{H} 4 \mathrm{M}$, and are therefore more susceptible to the molecule.

For FICIs of carvacrol, although no synergism was found for FICIs (Table 4), there was enhanced antifungal activity of $2 \mathrm{H} 4 \mathrm{M}$ and carvacrol for WT (FICIs $=1.0)$, except slt2 $\Delta$ and $b c k 1 \Delta$, for which FICI $=2.0$ (neutral interaction). For example, co-application of $2 \mathrm{H} 4 \mathrm{M}(0.8 \mathrm{mM})$ with carvacrol $(0.4 \mathrm{mM})$ completely inhibited the growth of WT in liquid culture (microtiter plate), while individual treatment of each compound, alone, at the same concentrations allowed the growth of WT.

For FFCIs of thymol, there was enhanced antifungal activity of $2 \mathrm{H} 4 \mathrm{M}$ and thymol for WT $($ FFCIs $=0.6)$, except slt $2 \Delta$ and $b c k 1 \Delta$, for which FFCI $=2.0$ (neutral interaction). For example, co-application of $2 \mathrm{H} 4 \mathrm{M}(0.8 \mathrm{mM})$ with thymol $(1.6 \mathrm{mM})$ resulted in complete inhibition of WT growth, while individual treatment of each compound, alone, at the same concentrations allowed the survival of the strain.

For FICIs of thymol, despite the absence of calculated synergism, there was increased antifungal activity of $2 \mathrm{H} 4 \mathrm{M}$ and thymol (viz., chemosensitizing effect; FICIs $=0.8$ to 1.0) in WT, slt2 $\Delta$ and $b c k 1 \Delta$, which was reflected in lowered MICs of $2 \mathrm{H} 4 \mathrm{M}$ and thymol when compounds were co-administered. For example, co-application of $2 \mathrm{H} 4 \mathrm{M}(0.8 \mathrm{mM}$ for all strains) with thymol $(0.4,0.4,0.2 \mathrm{mM}$ for WT, slt $2 \Delta$ and $b c k 1 \Delta$, respectively) completely inhibited the growth of yeast strains, while individual 
treatment of each compound, alone, at the same concentrations allowed the survival of yeasts (Table 4).

Collectively, 2H4M possessed a chemosensitizing capability to carvacrol or thymol in yeast tests, where MICs and MFCs of test compounds were decreased (viz., antifungal potency of test compounds was increased) during chemosensitization. Thymol required much lower concentration (viz., 0.2 to $0.4 \mathrm{mM}$ for FICIs; $1.6 \mathrm{mM}$ for FFCI) during chemosensitization compared to carvacrol (viz., $0.4 \mathrm{mM}$ for FICIs; $3.2 \mathrm{mM}$ for FFCIs) for complete inhibition of yeast growth, indicating structure-activity relationship also existed in monoterpenoid phenols. The "neutral interaction" determined in slt2 $\Delta$ and $b c k 1 \Delta$ during chemosensitization (viz., $\mathrm{FICI}_{\mathrm{CARVACROL}}$ or $\mathrm{FFCI}_{\mathrm{THYMOL}}=2.0$ ) indicated that the MICs of carvacrol for slt2 $\Delta$ and $b c k 1 \Delta(0.4 \mathrm{mM})$ or MFCs of thymol for the same mutants $(1.6 \mathrm{mM})$ already reached the maximum antimycotic level without chemosensitization, while WT required chemosensitization for the improvement of potency of test compounds. Thus, results further reflect the higher susceptibility of slt $2 \Delta$ and $b c k 1 \Delta$ mutants to cell wall disrupting reagents (i.e., $2 \mathrm{H} 4 \mathrm{M}$, monoterpenoid phenols) compared to WT.

Table 4. Antifungal chemosensitization of $2 \mathrm{H} 4 \mathrm{M}(\mathrm{mM})$ to carvacrol or thymol (mM), tested against S. cerevisiae strains: summary of EUCAST-based microdilution bioassays. ${ }^{\text {a }}$

\begin{tabular}{|c|c|c|c|c|c|c|c|}
\hline Yeast Strains Carvacrol & Compounds & $\begin{array}{l}\text { MIC } \\
\text { Alone }\end{array}$ & $\begin{array}{c}\text { MIC } \\
\text { Combined }\end{array}$ & FICI & $\begin{array}{l}\text { MFC } \\
\text { Alone }\end{array}$ & $\begin{array}{c}\text { MFC } \\
\text { Combined }\end{array}$ & FFCI \\
\hline \multirow{2}{*}{ S. cerevisiae WT } & Carvacrol & 0.8 & 0.4 & \multirow{2}{*}{1.0} & $6.4^{\mathrm{b}}$ & 3.2 & \multirow{2}{*}{0.8} \\
\hline & 2H4M & 1.6 & 0.8 & & $12.8^{\mathrm{c}}$ & 3.2 & \\
\hline \multirow{2}{*}{ S. cerevisiae slt $2 \Delta$} & Carvacrol & 0.4 & 0.4 & \multirow{2}{*}{2.0} & 6.4 & 3.2 & \multirow{2}{*}{0.6} \\
\hline & $2 \mathrm{H} 4 \mathrm{M}$ & 1.6 & 1.6 & & 12.8 & 1.6 & \\
\hline \multirow{2}{*}{ S. cerevisiae bck1 $\Delta$} & Carvacrol & 0.4 & 0.4 & \multirow{2}{*}{2.0} & 6.4 & 3.2 & \multirow{2}{*}{0.6} \\
\hline & $2 \mathrm{H} 4 \mathrm{M}$ & 0.8 & 0.8 & & 12.8 & 1.6 & \\
\hline \multirow{2}{*}{ Mean } & Carvacrol & 0.5 & 0.4 & \multirow{2}{*}{1.6} & 6.4 & 3.2 & \multirow{2}{*}{0.6} \\
\hline & $2 \mathrm{H} 4 \mathrm{M}$ & 1.3 & 1.1 & & 12.8 & 2.1 & \\
\hline \multirow{2}{*}{$t$-test ${ }^{d}$} & Carvacrol & - & $p<0.5$ & - & - & $p<0.005$ & - \\
\hline & $2 \mathrm{H} 4 \mathrm{M}$ & - & $p<1.0$ & - & - & $p<0.005$ & - \\
\hline Yeast Strains Thymol & Compounds & MIC & MIC & \multirow{2}{*}{ FICI } & MFC & MFC & \multirow{2}{*}{ FFCI } \\
\hline & & Alone & Combined & & Alone & Combined & \\
\hline \multirow{2}{*}{ S. cerevisiae WT } & Thymol & 1.6 & 0.4 & \multirow{2}{*}{0.8} & 3.2 & 1.6 & \multirow{2}{*}{0.6} \\
\hline & $2 \mathrm{H} 4 \mathrm{M}$ & 1.6 & 0.8 & & 12.8 & 0.8 & \\
\hline \multirow{2}{*}{ S. cerevisiae slt $2 \Delta$} & Thymol & 0.8 & 0.4 & \multirow{2}{*}{1.0} & 1.6 & 1.6 & \multirow{2}{*}{2.0} \\
\hline & $2 \mathrm{H} 4 \mathrm{M}$ & 1.6 & 0.8 & & 12.8 & 12.8 & \\
\hline \multirow{2}{*}{ S. cerevisiae bck1 $\Delta$} & Thymol & 0.8 & 0.2 & \multirow{2}{*}{0.8} & 1.6 & 1.6 & \multirow[b]{2}{*}{2.0} \\
\hline & $2 \mathrm{H} 4 \mathrm{M}$ & 1.6 & 0.8 & & 12.8 & 12.8 & \\
\hline \multirow{2}{*}{ Mean } & Thymol & 1.1 & 0.3 & \multirow{2}{*}{0.8} & 2.1 & 1.6 & \multirow{2}{*}{1.5} \\
\hline & $2 \mathrm{H} 4 \mathrm{M}$ & 1.6 & 0.8 & & 12.8 & 8.8 & \\
\hline \multirow{2}{*}{$t$-test ${ }^{\mathrm{d}}$} & Thymol & - & $p<0.1$ & - & - & $p<0.5$ & - \\
\hline & $2 \mathrm{H} 4 \mathrm{M}$ & - & $p=0.0$ & - & - & $p<0.5$ & - \\
\hline
\end{tabular}

${ }^{a}$ MIC, Minimum inhibitory concentration; MFC, Minimum fungicidal concentration; FICI, Fractional Inhibitory Concentration Indices; FFCI, Fractional Fungicidal Concentration Indices; ${ }^{\mathrm{b}}$ Carvacrol was tested up to $3.2 \mathrm{mM}$. For calculation purpose, $6.4 \mathrm{mM}$ (doubling of $3.2 \mathrm{mM}$ ) was used; ${ }^{\mathrm{c}} 2 \mathrm{H} 4 \mathrm{M}$ was tested up to $6.4 \mathrm{mM}$. For calculation purpose, $12.8 \mathrm{mM}$ (doubling of $6.4 \mathrm{mM}$ ) was used; ${ }^{\mathrm{d}}$ Student's $t$-test for paired data (combined, i.e., chemosensitization) was vs. mean MIC or MFC of each compound (alone, i.e., no chemosensitization) determined in yeast strains. 

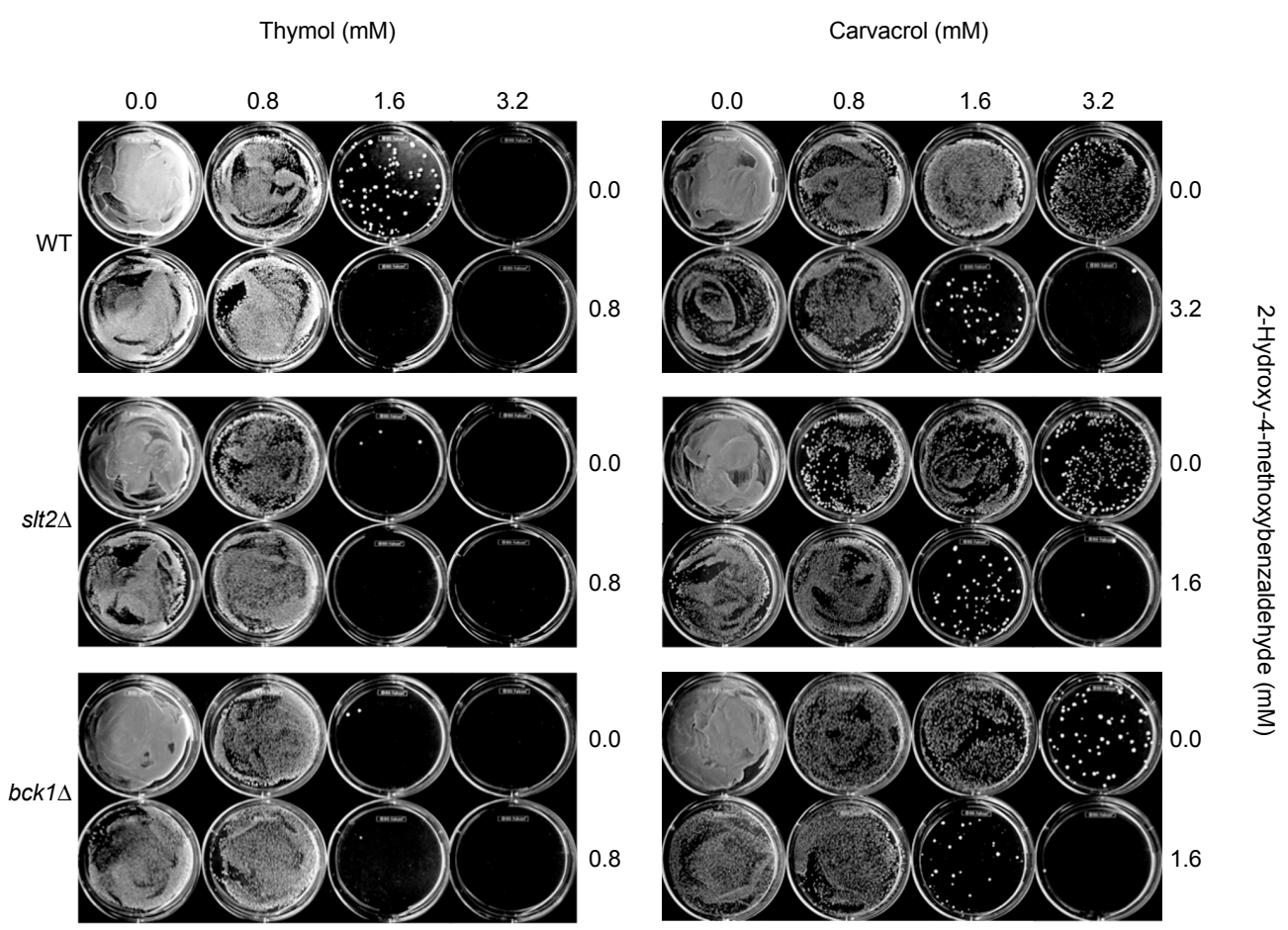

Figure 4. Chemosensitization test in $S$. cerevisiae (thymol or carvacrol $+2 \mathrm{H} 4 \mathrm{M}$ ). Exemplary plate bioassay showing co-application of thymol or carvacrol (1.6 to $3.2 \mathrm{mM}$ ) with $2 \mathrm{H} 4 \mathrm{M}$ (0.8 to $3.2 \mathrm{mM}$ ) completely inhibited the growth of $S$. cerevisiae strains (WT, slt2 $\Delta, b c k 1 \Delta)$.

\subsection{Chemosensitization Test in Filamentous Fungi: Co-Application of Thymol or Carvacrol with $2 H 4 M$}

Antifungal chemosensitization was further explored in filamentous fungal pathogens (Aspergillus, Penicillium) according to the CLSI microdilution bioassay protocol [44], where both MICs and MFCs, and thus, both FICIs and FFCIs, of fungal pathogens were determined (See Experimental section for concentrations of test compounds).

For FFCIs of carvacrol in Aspergillus, "synergistic" FFCI values (i.e., FFCI $\leqslant 0.5$ ) were found between carvacrol and 2H4M for all Aspergillus strains examined (FFCIs $=0.3$ to 0.4) (Table 5). Prior studies in yeasts showed that mutations in the antioxidant system, such as oxidative MAPK pathway, could result in the development of fungal resistance to cell wall perturbing agents [50-53]. Therefore, antioxidant mutants of $A$. fumigatus ( $\operatorname{sak} A \Delta, m p k C \Delta$ ) were also included in this study to determine whether antioxidant mutants of filamentous fungi develop resistance to $2 \mathrm{H} 4 \mathrm{M}$ or monoterpenoid phenols.

Results showed that oxidative MAPK mutants $(\operatorname{sak} A \Delta, m p k C \Delta)$ were more sensitive to carvacrol compared to $\mathrm{WT}$, where the carvacrol values of WT, sakA $\Delta$ or $m p k C \Delta$ were $(12.8,3.2,3.2 \mathrm{mM})$ for MFC $_{\mathrm{ALONE}}$ or $(1.6,0.8,0.8 \mathrm{mM})$ for $\mathrm{MFC}_{\mathrm{COMBINED}}$, respectively. It is surmised that, similar to other phenolics (See Introduction), carvacrol further exacerbated the vulnerability (namely, defects in countering oxidative stress or disruption of cellular redox homeostasis) of the antioxidant mutants ( $\operatorname{sak} A \Delta$ and $m p k C \Delta$ ) $[27,28]$ (See also Figure 5). Accordingly, besides the cell wall integrity MAPK system, the operation of the "intact" antioxidant MAPK pathway of A. fumigatus should also be important for pathogen's defense against carvacrol. In Penicillium, "synergistic" FFCI values were also determined for all Penicillium strains tested (FFCIs $=0.3$ to 0.4) (Table 5). Collectively, co-administration of $2 \mathrm{H} 4 \mathrm{M}$ with carvacrol lowered the MFCs of either compound (2H4M, carvacrol), which resulted in the achievement of synergism in all Aspergillus and Penicillium strains tested (Mean FFCI of filamentous fungi $=0.3$; Table 5 ). 
Table 5. Antifungal chemosensitization of $2 \mathrm{H} 4 \mathrm{M}(\mathrm{mM})$ to carvacrol or thymol (mM), tested against Aspergillus and Penicillium strains: summary of CLSI-based microdilution bioassays. ${ }^{\text {a }}$

\begin{tabular}{|c|c|c|c|c|c|c|c|}
\hline Fungal Strains & Compounds & MIC Alone & MIC Combined & FICI & MFC Alone & MFC Combined & FFCI \\
\hline \multirow{2}{*}{ A. fumigatus AF293 } & Carvacrol & 1.6 & 0.4 & \multirow[b]{2}{*}{0.8} & $12.8^{\mathrm{b}}$ & 1.6 & \multirow[b]{2}{*}{0.3} \\
\hline & $2 \mathrm{H} 4 \mathrm{M}$ & 0.8 & 0.4 & & $12.8^{\mathrm{c}}$ & 1.6 & \\
\hline \multirow{2}{*}{ A. fumigatus sak $A \Delta$} & Carvacrol & 1.6 & 0.4 & \multirow{2}{*}{0.8} & 3.2 & 0.8 & \multirow{2}{*}{0.4} \\
\hline & 2H4M & 0.8 & 0.4 & & 12.8 & 1.6 & \\
\hline \multirow{2}{*}{ A. fumigatus mpkC $\Delta$} & Carvacrol & 1.6 & 0.4 & \multirow{2}{*}{0.8} & 3.2 & 0.8 & \multirow{2}{*}{0.4} \\
\hline & 2H4M & 0.8 & 0.4 & & 12.8 & 1.6 & \\
\hline \multirow{2}{*}{ A. flavus 3357} & Carvacrol & 1.6 & 0.8 & \multirow{2}{*}{1.0} & 12.8 & 1.6 & \multirow[b]{2}{*}{0.4} \\
\hline & 2H4M & 0.8 & 0.4 & & 3.2 & 0.8 & \\
\hline \multirow{2}{*}{ A. flavus 4212} & Carvacrol & 1.6 & 0.8 & \multirow[b]{2}{*}{0.8} & 12.8 & 1.6 & \multirow[b]{2}{*}{0.4} \\
\hline & $2 \mathrm{H} 4 \mathrm{M}$ & 1.6 & 0.4 & & 3.2 & 0.8 & \\
\hline \multirow{2}{*}{ A. parasiticus 2999} & Carvacrol & 1.6 & 0.8 & \multirow{2}{*}{1.0} & 12.8 & 0.8 & \multirow{2}{*}{0.3} \\
\hline & 2H4M & 0.8 & 0.4 & & 6.4 & 1.6 & \\
\hline A parasiticus 5862 & Carvacrol & 1.6 & 0.8 & & 12.8 & 0.8 & \\
\hline A. parasiticus 5862 & 2H4M & 0.8 & 0.4 & 1.0 & 6.4 & 1.6 & 0.3 \\
\hline & Carvacrol & 0.8 & 0.2 & & 12.8 & 1.6 & \\
\hline P. expansum WI & $2 \mathrm{H} 4 \mathrm{M}$ & 0.4 & 0.2 & 0.8 & 12.8 & 3.2 & 0.4 \\
\hline P expansum $\mathrm{FR} 2$ & Carvacrol & 0.8 & 0.4 & 10 & 12.8 & 1.6 & \\
\hline & 2H4M & 0.4 & 0.2 & 1.0 & 12.8 & 1.6 & 0.3 \\
\hline P expansum W2 & Carvacrol & 1.6 & 0.8 & & 12.8 & 1.6 & \\
\hline P. еxрапsum WL & $2 \mathrm{H} 4 \mathrm{M}$ & 0.8 & 0.4 & 1.0 & 12.8 & 1.6 & 0.3 \\
\hline & Carvacrol & 0.8 & 0.4 & & 12.8 & 1.6 & \\
\hline P. expansum FR3 & $2 \mathrm{H} 4 \mathrm{M}$ & 0.8 & 0.4 & 1.0 & 12.8 & 1.6 & 0.3 \\
\hline Mean & Carvacrol & 1.4 & 0.6 & 09 & 11.1 & 1.3 & \\
\hline Mean & 2H4M & 0.8 & 0.4 & 0.9 & 9.9 & 1.6 & 0.3 \\
\hline & Carvacrol & - & $p<0.005$ & - & - & $p<0.005$ & - \\
\hline$t$-test ${ }^{a}$ & $2 \mathrm{H} 4 \mathrm{M}$ & - & $p<0.005$ & - & - & $p<0.005$ & - \\
\hline Fungal Strains & Compounds & MIC Alone & MIC Combined & FICI & MFC Alone & MFC Combined & FFCI \\
\hline A. fumigatus AF293 & Thymol & 1.6 & 0.4 & & 3.2 & 0.8 & \\
\hline A. fumigatus AF293 & $2 \mathrm{H} 4 \mathrm{M}$ & 0.8 & 0.4 & 0.8 & 12.8 & 3.2 & 0.5 \\
\hline A. fumigatus sak $A \Delta$ & Thymol & 1.6 & 0.4 & & 1.6 & 0.4 & \\
\hline A. Jumtgatus sakA口 & $2 \mathrm{H} 4 \mathrm{M}$ & 0.8 & 0.4 & 0.8 & 12.8 & 3.2 & 0.5 \\
\hline A fumigatus mpkCA & Thymol & 1.6 & 0.4 & & 1.6 & 0.4 & \\
\hline A. fumigatus mpkс $\Delta$ & $2 \mathrm{H} 4 \mathrm{M}$ & 0.8 & 0.4 & 0.8 & 12.8 & 3.2 & 0.5 \\
\hline A flavus 3357 & Thymol & 1.6 & 0.4 & & 3.2 & 1.6 & \\
\hline A. flavus 335\% & $2 \mathrm{H} 4 \mathrm{M}$ & 1.6 & 0.8 & 0.8 & 3.2 & 0.4 & 0.6 \\
\hline A. flavus 4212 & Thymol & 1.6 & 0.4 & & 3.2 & 1.6 & 06 \\
\hline A. flavus 4212 & $2 \mathrm{H} 4 \mathrm{M}$ & 1.6 & 0.8 & 0.8 & 3.2 & 0.4 & 0.6 \\
\hline A parasiticus 2999 & Thymol & 1.6 & 0.8 & & $12.8^{\mathrm{e}}$ & 0.8 & \\
\hline A. parasiticus 2999 & $2 \mathrm{H} 4 \mathrm{M}$ & 0.8 & 0.4 & 1.0 & $6.4^{\mathrm{f}}$ & 1.6 & 0.3 \\
\hline A parasiticus 5862 & Thymol & 1.6 & 0.8 & & 12.8 & 0.8 & \\
\hline A. parasttcus 5862 & $2 \mathrm{H} 4 \mathrm{M}$ & 0.8 & 0.4 & 1.0 & $6.4^{\mathrm{f}}$ & 1.6 & 0.3 \\
\hline P. expansum W1 & Thymol & 0.8 & 0.4 & & 12.8 & 1.6 & \\
\hline P. expansum w1 & 2H4M & 0.4 & 0.2 & 1.0 & 12.8 & 1.6 & 0.3 \\
\hline P. expansum FR2 & Thymol & 0.8 & 0.4 & 10 & 12.8 & 1.6 & 02 \\
\hline P. еxpansum FK2 & $2 \mathrm{H} 4 \mathrm{M}$ & 0.4 & 0.2 & 1.0 & 12.8 & 1.6 & 0.3 \\
\hline & Thymol & 1.6 & 0.8 & & 12.8 & 1.6 & \\
\hline P. expansum W2 & $2 \mathrm{H} 4 \mathrm{M}$ & 0.8 & 0.4 & 1.0 & 12.8 & 1.6 & 0.3 \\
\hline$P$ expansum $\mathrm{ER} 3$ & Thymol & 0.8 & 0.4 & & 12.8 & 1.6 & \\
\hline P. еxpansum FK3 & $2 \mathrm{H} 4 \mathrm{M}$ & 0.8 & 0.4 & 1.0 & 12.8 & 1.6 & 0.3 \\
\hline & Thymol & 1.4 & 0.5 & & 8.1 & 1.2 & \\
\hline Mean & $2 \mathrm{H} 4 \mathrm{M}$ & 0.9 & 0.4 & 0.8 & 9.9 & 1.8 & 0.3 \\
\hline & Thymol & - & $p<0.005$ & - & - & $p<0.005$ & - \\
\hline$t$-test & 2H4M & - & $p<0.005$ & - & - & $p<0.005$ & - \\
\hline
\end{tabular}

a MIC, Minimum inhibitory concentration; MFC, Minimum fungicidal concentration; FICI, Fractional Inhibitory Concentration Indices; FFCI, Fractional Fungicidal Concentration Indices. Synergistic FICIs and FFCI are in bold; ${ }^{b}$ Carvacrol was tested up to $6.4 \mathrm{mM}$. For calculation purpose, $12.8 \mathrm{mM}$ (doubling of $6.4 \mathrm{mM}$ ) was used; ' ${ }^{c} 2 \mathrm{H} 4 \mathrm{M}$ was tested up to $6.4 \mathrm{mM}$. For calculation purpose, $12.8 \mathrm{mM}$ (doubling of $6.4 \mathrm{mM}$ ) was used; $^{\mathrm{d}}$ Student's $t$-test for paired data (combined, i.e., chemosensitization) was vs. mean MIC or MFC of each compound (alone, i.e., no chemosensitization) determined in strains; ${ }^{\mathrm{e}}$ Thymol was tested up to $6.4 \mathrm{mM}$. For calculation purpose, $12.8 \mathrm{mM}$ (doubling of $6.4 \mathrm{mM}$ ) was used; ${ }^{\mathrm{f}} 99.8 \%$ killing. 
(a)

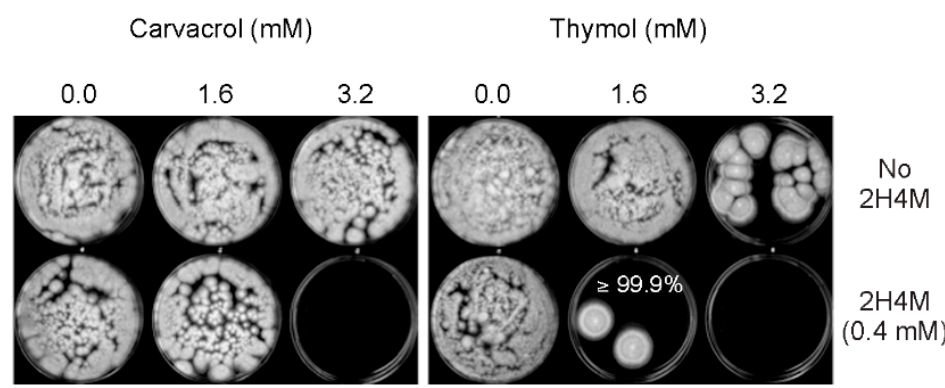

A. flavus 4212

(b)

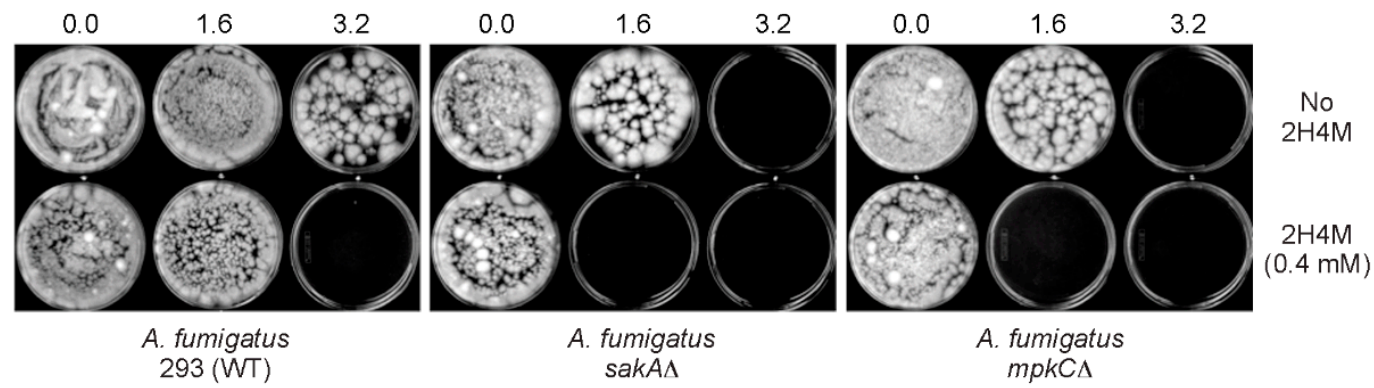

Figure 5. Chemosensitization test in aflatoxigenic Aspergillus or A. fumigatus (thymol or carvacrol $+2 \mathrm{H} 4 \mathrm{M})$. Exemplary bioassay showing co-application of thymol or carvacrol with $2 \mathrm{H} 4 \mathrm{M}$ completely inhibited the growth of (a) aflatoxigenic A. flavus 4212 or (b) A. fumigatus. Results also showed that oxidative MAPK mutants ( $\operatorname{sak} A, m p k C \Delta$ ) were more sensitive to the chemosensitization compared to WT (Concentrations presented: 1.6 to $3.2 \mathrm{mM}$, carvacrol or thymol; $0.4 \mathrm{mM}, 2 \mathrm{H} 4 \mathrm{M}$ ).

Regarding FICIs of carvacrol in Aspergillus, enhanced activity of $2 \mathrm{H} 4 \mathrm{M}$ or carvacrol was also identified during chemosensitization (FICIs $=0.8$ to 1.0 ), although there was no calculated synergism. For example, co-application of $2 \mathrm{H} 4 \mathrm{M}(0.4 \mathrm{mM})$ with carvacrol $(0.8 \mathrm{mM})$ achieved complete inhibition of $A$. parasiticus growth, while individual treatment of each compound, alone, at the same concentrations resulted in the survival of $A$. parasiticus. However, unlike the MFC testing (See above), the sakA $\triangle$ and $m p k C \Delta$ mutants did not show higher sensitivity to carvacrol during MIC testing, when compared to WT (Table 5). In Penicillium, despite the no calculated synergism, enhanced activity of $2 \mathrm{H} 4 \mathrm{M}$ and carvacrol was also found in all test strains, where FICIs were 0.8 to 1.0. Altogether, co-application of $2 \mathrm{H} 4 \mathrm{M}$ and carvacrol resulted in enhancement of antifungal activity of either compound during FICI determination (Mean FICI of filamentous fungi = 0.9; See Table 5).

For FFCIs of thymol in Aspergillus, synergistic FFCIs were identified in A. fumigatus (FFCI = 0.5) and $A$. parasiticus $(\mathrm{FFCI}=0.3$ ). Although no synergism was identified, there was elevated antifungal activity of $2 \mathrm{H} 4 \mathrm{M}$ and thymol in A. flavus strains (FFCI = 0.6) during chemosensitization (Table 5). As observed in carvacrol test (See above), A. fumigatus oxidative MAPK mutants ( $\operatorname{sak} A \Delta, m p k C \Delta$ ) were more susceptible to thymol compared to WT, where the thymol values of WT, sakA $\triangle$ or $m p k C \Delta$ were $(3.2,1.6,1.6 \mathrm{mM})$ for $\mathrm{MFC}_{\mathrm{ALONE}}$ or $(0.8,0.4,0.4 \mathrm{mM})$ for $\mathrm{MFC}_{\mathrm{COMBINED}}$, respectively. Higher susceptibility to thymol (compared to carvacrol) was also observed in A. flavus (3357, 4212) (for example, MIC COMBINED $_{\text {or MFC }}$ ALONE of thymol or carvacrol was $(0.4$ vs. $0.8 \mathrm{mM})$ for MIC $_{\text {COMBINED }}$ or (3.2 vs. $12.8 \mathrm{mM}$ ) for $\mathrm{MFC}_{\mathrm{ALONE}}$, respectively; Table 5). However, the level of antimycotic activity of carvacrol or thymol was vastly similar in $A$. parasiticus or $P$. expansum strains, except MIC COMBINED of $P$. expansum W1 (viz., MIC COMBINED for carvacrol or thymol was 0.2 or $0.4 \mathrm{mM}$, respectively). In Penicillium, "synergistic" FFCI values were also determined in all Penicillium strains tested $($ FFCIs $=0.3$ ) (Table 5). Altogether, co-application of 2H4M and thymol resulted in 
enhancement of antifungal activity of either compound during FFCI determination (Mean FFCI of filamentous fungi = 0.3; See Table 5). The MFC values of thymol were, in general, lower than that of carvacrol, indicating that, as observed in S. cerevisiae (See above), thymol possessed higher antimycotic potency in selected fungi.

Regarding FICIs of thymol in Aspergillus, enhanced antimycotic activity of 2H4M or thymol was also identified during chemosensitization (FICIs $=0.8$ to 1.0 ), despite the no calculated synergism. For example, co-application of $2 \mathrm{H} 4 \mathrm{M}(0.4 \mathrm{mM})$ with thymol $(0.8 \mathrm{mM})$ resulted in complete inhibition of $A$. parasiticus growth in liquid culture, while individual treatment of each compound, alone, at the same concentrations allowed the survival of $A$. parasiticus. However, unlike the MFC testing (See above), the sakA $\Delta$ and $m p k C \Delta$ mutants did not show higher sensitivity to thymol compared to WT in MIC testing (Table 5). In Penicillium, despite not achieving calculated synergism, enhanced activity of $2 \mathrm{H} 4 \mathrm{M}$ and thymol was also identified in all test strains, where FICIs were 1.0. Collectively, co-application of $2 \mathrm{H} 4 \mathrm{M}$ and thymol achieved the enhancement of antifungal activity of either compound during FICI determination (Mean FICI of filamentous fungi $=0.8$; See Table 5).

\subsection{Overcoming Fludioxonil Tolerance of A. fumigatus MAPK Mutants by $2 \mathrm{H} 4 \mathrm{M}$ Co-Treatment}

Fludioxonil, a conventional phenylpyrrole fungicide, elicits excessive stimulation of the intact MAPK signaling pathway, which is responsive to high osmotic/oxidative stress [54]. Thus, the immoderate activation of the osmotic/oxidative MAPK signaling system (HOG1 in S. cerevisiae) by fludioxonil results in an energy drain via metabolic shifts from normal growth to exhaustive stress response. Consequently, treatment of fungi with fludioxonil prevents the normal growth of fungal cells. However, fungal strains having mutations in genes of upstream signal transduction pathway, such as osmotic/oxidative MAPK signaling pathway, can evade toxicity exerted by fludioxonil [54]. We demonstrated that $A$. fumigatus MAPK mutants (sakA $\Delta, m p k C \Delta$ ) exhibited tolerance to $50 \mu \mathrm{M}$ fludioxonil (thus, were able to develop radial growth on agar), while the growth of WT (AF293) was completely inhibited (Figure 6). However, co-application of sub-fungicidal concentration of 2H4M (at $0.8 \mathrm{mM}$, where the fungal growth rate was almost not inhibited) with fludioxonil achieved the prevention of fungal tolerance to the fungicide, which resulted in complete growth inhibition of MAPK mutants (sakA $\Delta, m p k C \Delta$ ) (Figure 6). Cell wall disrupting agents, such as echinocandin drugs, lyse the actively growing hyphal tips of fungi during filamentous fungal growth [23]. It is speculated that the cell wall disturbing capability of $2 \mathrm{H} 4 \mathrm{M}$ can enhance the penetration of fludioxonil into the MAPK mutants through perturbed cell wall, which results in complete inhibition of the growth of A. fumigatus sakA $\triangle$ and $m p k C \Delta$ on fludioxonil-containing plates.

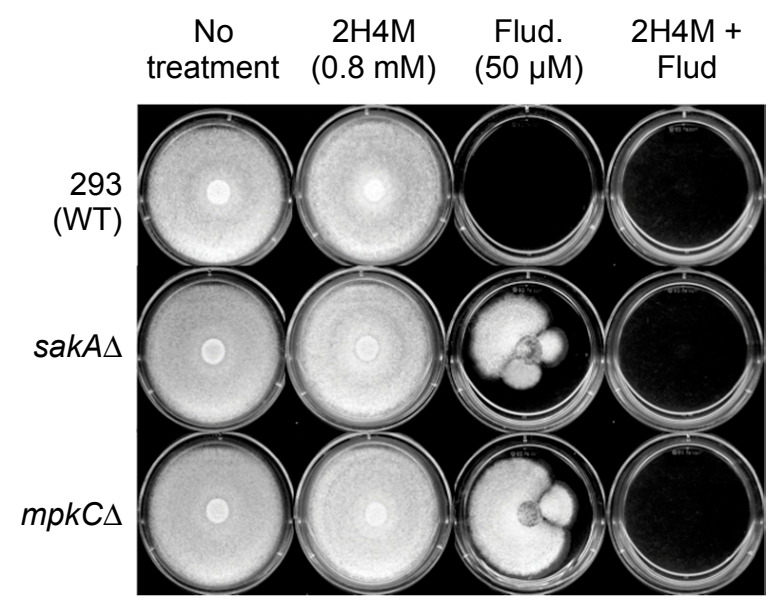

Figure 6. Overcoming fludioxonil tolerance of $A$. fumigatus MAPK mutants (sakA $\Delta, m p k C \Delta$ ) by $2 \mathrm{H} 4 \mathrm{M}$ (agar plate bioassay). 


\subsection{Antimycotoxigenic Property of $2 \mathrm{H} 4 \mathrm{M}$ against $A$. parasiticus Strains}

As mentioned previously (See Introduction), sub-optimal application of fungicide can potentiate the production of mycotoxins in various fungal pathogens. Therefore, the effect of the antimycotic $2 \mathrm{H} 4 \mathrm{M}$, thymol and carvacrol on the production of aflatoxins (AFs) was evaluated in the mycotoxigenic Aspergillus strains, i.e., A. flavus 3357, 4212 and A. parasiticus 2999, 5862. Test compounds were administered at sub-MICs or MFCs $(0.125$ to $1.000 \mathrm{mM})$, where the sclerotial development was also monitored.

In A. flavus, administration of thymol and carvacrol at 0.125 to $0.500 \mathrm{mM}(0.125$ to $0.250 \mathrm{mM}$ for $2 \mathrm{H} 4 \mathrm{M})$ enhanced the production of aflatoxins $\left(\mathrm{AFB}_{1}, \mathrm{AFB}_{2}\right.$; See Figure 1 for structures) compared to control (no treatment) (Table 6). Results indicated that, like other commercial fungicides (See Introduction), carvacrol, thymol or $2 \mathrm{H} 4 \mathrm{M}$ could potentiate the biosynthesis of mycotoxins in fungi. However, mycotoxin production was lowered at $>0.500 \mathrm{mM}$ of monoterpenoid phenols (compared to no treatment control), while fungal growth (accordingly, mycotoxin production) was completely inhibited at $\geqslant 0.500 \mathrm{mM}$ of $2 \mathrm{H} 4 \mathrm{M}$, reflecting higher antifungal potency of $2 \mathrm{H} 4 \mathrm{M}$ compared to thymol or carvacrol (There was an observable growth defect across fungal species at 0.5 to $1.0 \mathrm{mM}$ concentrations of each antifungal).

Table 6. Effect of $2 \mathrm{H} 4 \mathrm{M}$ and monoterpenoid phenols on the production of aflatoxins and sclerotia. Increased values compared to no treatment control are in bold characters. ${ }^{\text {a }}$

\begin{tabular}{|c|c|c|c|c|c|c|}
\hline \multicolumn{7}{|c|}{ Thymol } \\
\hline Strains & Concentration & $\mathbf{A F B}_{1}$ & $\mathbf{A F B}_{2}$ & $\mathrm{AFG}_{1}$ & $\mathrm{AFG}_{2}$ & Sclerotia \\
\hline \multirow{5}{*}{ A. flavus 3357} & 0.000 & $5.14 \pm 0.87$ & $0.07 \pm 0.02$ & $-b$ & - & $6 \pm 6$ \\
\hline & 0.125 & $7.38 \pm 0.31$ & $0.14 \pm 0.01$ & - & - & $47 \pm 5$ \\
\hline & 0.250 & $7.74 \pm 1.16$ & $0.14 \pm 0.02$ & - & - & $84 \pm 7$ \\
\hline & 0.500 & $8.72 \pm 0.36$ & $0.19 \pm 0.01$ & - & - & $31 \pm 9$ \\
\hline & 1.000 & $1.16 \pm 0.48$ & $0.01 \pm 0.00$ & - & - & $0 \pm 0$ \\
\hline \multirow{5}{*}{ A. flavus 4212} & 0.000 & $4.55 \pm 0.08$ & $0.02 \pm 0.00$ & - & - & $0 \pm 0$ \\
\hline & 0.125 & $5.86 \pm 0.15$ & $0.03 \pm 0.01$ & - & - & $0 \pm 0$ \\
\hline & 0.250 & $6.77 \pm 0.38$ & $0.05 \pm 0.01$ & - & - & $3 \pm 2$ \\
\hline & 0.500 & $7.15 \pm 0.12$ & $0.06 \pm 0.01$ & - & - & $0 \pm 0$ \\
\hline & 1.000 & $1.56 \pm 0.47$ & $0.01 \pm 0.00$ & - & - & $0 \pm 0$ \\
\hline \multirow{5}{*}{ A. parasiticus 2999} & 0.000 & $14.46 \pm 0.31$ & $0.25 \pm 0.01$ & $3.07 \pm 0.18$ & $0.12 \pm 0.01$ & $0 \pm 0$ \\
\hline & 0.125 & $18.80 \pm 0.06$ & $0.50 \pm 0.01$ & $5.93 \pm 0.06$ & $0.30 \pm 0.01$ & $171 \pm 23$ \\
\hline & 0.250 & $23.16 \pm 1.26$ & $0.71 \pm 0.06$ & $7.65 \pm 0.82$ & $0.41 \pm 0.04$ & $28 \pm 13$ \\
\hline & 0.500 & $18.19 \pm 0.50$ & $0.49 \pm 0.01$ & $3.96 \pm 0.35$ & $0.17 \pm 0.03$ & $0 \pm 0$ \\
\hline & 1.000 & $0.90 \pm 0.44$ & $0.01 \pm 0.00$ & $0.02 \pm 0.01$ & $0.00 \pm 0.00$ & $0 \pm 0$ \\
\hline \multirow{5}{*}{ A. parasiticus 5862} & 0.000 & $15.01 \pm 0.92$ & $0.27 \pm 0.02$ & $3.39 \pm 0.24$ & $0.14 \pm 0.01$ & $0 \pm 0$ \\
\hline & 0.125 & $18.64 \pm 1.60$ & $0.49 \pm 0.06$ & $5.98 \pm 0.83$ & $0.30 \pm 0.03$ & $166 \pm 21$ \\
\hline & 0.250 & $22.69 \pm 1.38$ & $0.69 \pm 0.07$ & $7.54 \pm 0.82$ & $0.40 \pm 0.06$ & $17 \pm 13$ \\
\hline & 0.500 & $16.34 \pm 1.49$ & $0.44 \pm 0.05$ & $3.32 \pm 0.48$ & $0.16 \pm 0.04$ & $0 \pm 0$ \\
\hline & 1.000 & $0.69 \pm 0.22$ & $0.01 \pm 0.00$ & $0.01 \pm 0.01$ & $0.00 \pm 0.00$ & $0 \pm 0$ \\
\hline \multicolumn{7}{|c|}{ Carvacrol } \\
\hline Strains & Concentration & $\mathbf{A F B}_{1}$ & $\mathbf{A F B}_{2}$ & $\mathrm{AFG}_{1}$ & $\mathrm{AFG}_{2}$ & Sclerotia \\
\hline \multirow{5}{*}{ A. flavus 3357} & 0.000 & $4.80 \pm 0.14$ & $0.06 \pm 0.00$ & $-\mathrm{b}$ & - & $2 \pm 1$ \\
\hline & 0.125 & $5.78 \pm 0.31$ & $0.09 \pm 0.01$ & - & - & $64 \pm 11$ \\
\hline & 0.250 & $5.73 \pm 0.53$ & $0.10 \pm 0.01$ & - & - & $59 \pm 8$ \\
\hline & 0.500 & $5.96 \pm 0.36$ & $0.13 \pm 0.01$ & - & - & $0 \pm 0$ \\
\hline & 1.000 & $1.23 \pm 0.45$ & $0.01 \pm 0.01$ & - & - & $0 \pm 0$ \\
\hline \multirow{5}{*}{ A. flavus 4212} & 0.000 & $5.51 \pm 0.56$ & $0.03 \pm 0.01$ & - & - & $0 \pm 0$ \\
\hline & 0.125 & $6.84 \pm 0.66$ & $0.05 \pm 0.01$ & - & - & $1 \pm 2$ \\
\hline & 0.250 & $7.50 \pm 0.66$ & $0.07 \pm 0.01$ & - & - & $8 \pm 4$ \\
\hline & 0.500 & $6.50 \pm 0.29$ & $0.07 \pm 0.01$ & - & - & $0 \pm 0$ \\
\hline & 1.000 & $0.91 \pm 0.32$ & $0.01 \pm 0.00$ & - & - & $0 \pm 0$ \\
\hline
\end{tabular}


Table 6. Cont.

\begin{tabular}{|c|c|c|c|c|c|c|}
\hline \multicolumn{7}{|c|}{ Carvacrol } \\
\hline Strains & Concentration & $\mathbf{A F B}_{1}$ & $\mathbf{A F B}_{2}$ & $\mathrm{AFG}_{1}$ & $\mathrm{AFG}_{2}$ & Sclerotia \\
\hline \multirow{5}{*}{ A. parasiticus 2999} & 0.000 & $14.02 \pm 1.58$ & $0.25 \pm 0.06$ & $2.75 \pm 0.54$ & $0.12 \pm 0.03$ & $1 \pm 1$ \\
\hline & 0.125 & $17.30 \pm 0.83$ & $0.37 \pm 0.03$ & $3.22 \pm 0.27$ & $0.14 \pm 0.01$ & $62 \pm 4$ \\
\hline & 0.250 & $17.38 \pm 0.26$ & $0.43 \pm 0.01$ & $2.90 \pm 0.12$ & $0.13 \pm 0.01$ & $46 \pm 5$ \\
\hline & 0.500 & $19.54 \pm 0.88$ & $0.52 \pm 0.04$ & $2.20 \pm 0.13$ & $0.08 \pm 0.00$ & $0 \pm 0$ \\
\hline & 1.000 & $0.09 \pm 0.04$ & $0.00 \pm 0.00$ & $0.00 \pm 0.00$ & $0.00 \pm 0.00$ & $0 \pm 0$ \\
\hline \multirow{5}{*}{ A. parasiticus 5862} & 0.000 & $13.92 \pm 0.36$ & $0.23 \pm 0.02$ & $2.84 \pm 0.10$ & $0.10 \pm 0.02$ & $1 \pm 1$ \\
\hline & 0.125 & $16.65 \pm 0.88$ & $0.35 \pm 0.03$ & $3.19 \pm 0.28$ & $0.12 \pm 0.01$ & $44 \pm 6$ \\
\hline & 0.250 & $16.51 \pm 1.07$ & $0.39 \pm 0.04$ & $2.68 \pm 0.22$ & $0.11 \pm 0.01$ & $25 \pm 3$ \\
\hline & 0.500 & $20.10 \pm 0.49$ & $0.52 \pm 0.03$ & $2.32 \pm 0.10$ & $0.07 \pm 0.01$ & $0 \pm 0$ \\
\hline & 1.000 & $0.12 \pm 0.12$ & $0.00 \pm 0.00$ & $0.00 \pm 0.00$ & $0.00 \pm 0.00$ & $0 \pm 0$ \\
\hline \multicolumn{7}{|c|}{$2 \mathrm{H} 4 \mathrm{M}$} \\
\hline Strains & Concentration & $\mathrm{AFB}_{1}$ & $\mathrm{AFB}_{2}$ & $\mathrm{AFG}_{1}$ & $\mathrm{AFG}_{2}$ & Sclerotia \\
\hline \multirow{5}{*}{ A. flavus 3357} & 0.000 & $4.73 \pm 0.23$ & $0.06 \pm 0.01$ & $-b$ & - & $4 \pm 3$ \\
\hline & 0.125 & $5.03 \pm 0.35$ & $0.08 \pm 0.01$ & - & - & $0 \pm 0$ \\
\hline & 0.250 & $4.84 \pm 0.06$ & $0.10 \pm 0.01$ & - & - & $0 \pm 0$ \\
\hline & 0.500 & $\mathrm{NG}^{\mathrm{c}}$ & NG & NG & NG & NG \\
\hline & 1.000 & NG & NG & NG & NG & NG \\
\hline \multirow{5}{*}{ A. flavus 4212} & 0.000 & $4.72 \pm 0.24$ & $0.02 \pm 0.01$ & - & - & $0 \pm 0$ \\
\hline & 0.125 & $6.58 \pm 1.02$ & $0.05 \pm 0.01$ & - & - & $0 \pm 0$ \\
\hline & 0.250 & $5.69 \pm 0.55$ & $0.04 \pm 0.01$ & - & - & $0 \pm 0$ \\
\hline & 0.500 & NG & NG & NG & NG & $\mathrm{NG}$ \\
\hline & 1.000 & NG & NG & NG & NG & NG \\
\hline \multirow{5}{*}{ A. parasiticus 2999} & 0.000 & $15.92 \pm 1.28$ & $0.27 \pm 0.04$ & $3.20 \pm 0.33$ & $0.13 \pm 0.03$ & $0 \pm 1$ \\
\hline & 0.125 & $12.80 \pm 0.26$ & $0.24 \pm 0.01$ & $2.62 \pm 0.08$ & $0.12 \pm 0.00$ & $0 \pm 0$ \\
\hline & 0.250 & $10.16 \pm 0.79$ & $0.17 \pm 0.02$ & $2.23 \pm 0.24$ & $0.06 \pm 0.02$ & $0 \pm 0$ \\
\hline & 0.500 & NG & NG & NG & NG & NG \\
\hline & 1.000 & NG & NG & NG & NG & NG \\
\hline \multirow{5}{*}{ A. parasiticus 5862} & 0.000 & $14.21 \pm 1.02$ & $0.23 \pm 0.03$ & $2.91 \pm 0.35$ & $0.11 \pm 0.01$ & $0 \pm 1$ \\
\hline & 0.125 & $12.65 \pm 0.53$ & $0.23 \pm 0.02$ & $2.65 \pm 0.07$ & $0.10 \pm 0.01$ & $0 \pm 0$ \\
\hline & 0.250 & $10.95 \pm 1.19$ & $0.19 \pm 0.04$ & $2.38 \pm 0.43$ & $0.06 \pm 0.02$ & $0 \pm 0$ \\
\hline & 0.500 & NG & NG & NG & NG & NG \\
\hline & 1.000 & NG & NG & NG & NG & NG \\
\hline
\end{tabular}

a Thymol, Carvacrol, $2 \mathrm{H} 4 \mathrm{M}$ : $\mathrm{mM}$; aflatoxins: $\mu \mathrm{g} / \mathrm{cm}^{2}$; Sclerotia: numbers per plate; ${ }^{\mathrm{b}}$ Below the detection limit; ${ }^{c}$ NG, No growth (accordingly, no aflatoxin detected).

In A. parasiticus, treatment of fungi with thymol and carvacrol at 0.125 to $0.500 \mathrm{mM}$ also enhanced the production of aflatoxins $\left(\mathrm{AFB}_{1}, \mathrm{AFB}_{2}, \mathrm{AFG}_{1}, \mathrm{AFG}_{2}\right.$; See Figure 1 for structures) compared to control (no treatment) (Table 6). As observed in A. flavus, mycotoxin production was lowered at $>0.500 \mathrm{mM}$ of monoterpenoid phenols (compared to no treatment control), while fungal growth (accordingly, mycotoxin production) was also completely prevented at $\geqslant 0.500 \mathrm{mM}$ of $2 \mathrm{H} 4 \mathrm{M}$. In general, A. parasiticus produced higher amounts of aflatoxins compared to A. flavus, when treated with thymol or carvacrol (See Table 6).

Notable observation is that, unlike the A. flavus strains, 2H4M actually inhibited the aflatoxin production in A. parasiticus at all test concentrations (Table 6), where the level of inhibition was commensurate with the $2 \mathrm{H} 4 \mathrm{M}$ concentration. Therefore, results strongly indicated that "strain specificity" also existed for the "antimycotoxigenic activity" of 2H4M.

Of note, in a prior study, oxidative stress regulated the sclerotial differentiation, where application of antioxidant modulators of reactive oxygen species prohibited the development of sclerotia [55]. Furthermore, aflatoxin biosynthesis and sclerotial differentiation were co-modulated by oxidative stress [55]. Therefore, sclerotial development/differentiation is considered as the indicator of fungal stress response, especially to oxidative stress.

In this study, treatment of $A$. flavus or A parasiticus strains with thymol or carvacrol also enhanced the sclerotial differentiation, depending on dosages and types of test compounds. 
A. flavus 3357 produced higher number of sclerotia compared to A. flavus 4212 (with both thymol and carvacrol), while $A$. parasiticus strains developed more sclerotia with thymol than with carvacrol (Table 6). Conversely, sclerotia development was almost not detected with the treatment of 2H4M, strongly indicating that: (1) the mechanism of action of $2 \mathrm{H} 4 \mathrm{M}$ for the antifungal or antimycotoxigenic activity against Aspergillus strains is considered to be different from that of monoterpenoid phenols; and (2) antifungal or antimycotoxigenic activity is dependent upon types (or species) of Aspergillus strains examined. Noteworthy is the effect of cell wall stress in the production of the secondary metabolite pyomelanin in A. fumigatus. Previous study showed that pyomelanin production was enhanced when constitutive cell wall stress was applied to A. fumigatus [56], strongly indicating the link between secondary metabolite production and cell wall stress. Recent study further revealed that genes involved in the pyomelanin synthesis were all up-regulated when the cell wall integrity MAPK mutant $\triangle m p k A$ was cultured under cell wall stress [57].

The strain specificity for the differential antimycotoxigenic activity with $2 \mathrm{H} 4 \mathrm{M}$ (i.e., A. flavus vs. A. parasiticus), as determined in this study, is a new observation, which may reflect the different level of cell wall stress triggered by $2 \mathrm{H} 4 \mathrm{M}$ in pathogens, depending on types of fungal species. Precise determination of the mechanism of differential activity regarding the antifungal or antimycotoxigenic activity of $2 \mathrm{H} 4 \mathrm{M}$ warrants future study.

\section{Experimental Section}

\subsection{Fungal Strains and Culture Conditions}

Fungal strains used in this study are summarized in Table 2. Aspergillus and Penicillium strains were grown at $35^{\circ} \mathrm{C}$ and $28^{\circ} \mathrm{C}$ (Forma Scientific, Marietta, $\mathrm{OH}, \mathrm{USA}$ ), respectively, on potato dextrose agar (PDA). Saccharomyces cerevisiae wild type (WT) BY4741 (Mat a his3 $\Delta 1$ leu2 $\Delta 0$ met15 $\Delta 0$ ura $\Delta \Delta 0$ ) and selected single gene deletion mutants $(b c k 1 \Delta$, slt $2 \Delta)$ were procured from Invitrogen (Carlsbad, CA, USA) and Open Biosystems (Huntsville, AL, USA; See also Saccharomyces Genome Database [30]). Yeast strains were cultured on Synthetic Glucose (SG; Yeast nitrogen base without amino acids $0.67 \%$, glucose $2 \%$ with appropriate supplements: uracil $0.02 \mathrm{mg} / \mathrm{mL}$, amino acids $0.03 \mathrm{mg} / \mathrm{mL}$ ) or Yeast Peptone Dextrose (YPD; Bacto yeast extract $1 \%$, Bacto peptone $2 \%$, glucose $2 \%$ ) medium at $30^{\circ} \mathrm{C}$. All chemicals for culturing fungi were procured from Sigma Co. (St. Louis, MO, USA).

\subsection{Chemicals}

Benzaldehyde (basal structure) and its structural analogs (i.e., fourteen benzaldehyde derivatives; See Figure 1), two monoterpenoid phenols (thymol, carvacrol; cell wall integrity disruptors), caffeine, sorbitol, and fludioxonil (fungicide) were procured from Sigma Co. (St. Louis, MO, USA). Each compound was dissolved in dimethylsulfoxide (DMSO from AMRESCO (Solon, $\mathrm{OH}, \mathrm{USA}$ ); absolute DMSO amount: $<2 \%$ in media) before incorporation into culture media (except for those plates used in aflatoxin assays; see below). In all tests, control plates (i.e., No treatment) contained DMSO at levels equivalent to that of cohorts receiving antifungal agents, within the same set of experiments (See Tables and Figures).

\subsection{Susceptibility Testing}

\subsubsection{Agar Plate Bioassay in S. cerevisiae}

Petri plate-based yeast dilution bioassays were performed on the WT and mutants ( $\operatorname{lt} 2 \Delta, b c k 1 \Delta)$ to assess effects of screened compounds on the cell wall integrity system. Yeast strains were exposed to 1 to $5 \mathrm{mM}$ of benzaldehyde analogs screened. $1 \times 10^{6}$ cells of the WT or cell wall integrity mutants $(b c k 1 \Delta$, slt $2 \Delta)$ of S. cerevisiae, cultured on YPD plate, were serially diluted 10-fold in SG liquid medium supplemented with amino acids and uracil (See above) five times to yield cell dilution cohorts of $10^{6}$, $10^{5}, 10^{4}, 10^{3}, 10^{2}$ and $10^{1}$ cells. Cells from each dilution of respective strains were spotted on SG 
agar incorporated with individual compounds, such as benzaldehyde analogs or other test reagents. Yeast cells were incubated at $30^{\circ} \mathrm{C}$. Results were monitored/evaluated based on a designated value of the highest dilution where colonies became visible after 5 to 7 days of incubation, as follows: Score " 0 " - no colonies were visible from any of the dilutions, Score " 1 "—only a colony from the spot with the undiluted cells $\left(10^{6}\right.$ cells), Score " 2 " only colonies from the spots with the undiluted $\left(10^{6}\right)$ and $10^{5}$ cells were visible, etc., while Score " 6 " - colonies were visible from all dilution spots. Therefore, each unit (1 to 6) of numerical difference was equivalent to a 10 -fold difference in the sensitivity of the yeast strain to the treatment.

\subsubsection{Agar Plate Bioassay in Aspergillus: Overcoming Fludioxonil Resistance of A. fumigatus sakA $\Delta$} and $m p k C \Delta$ Mutants

Measurement of overcoming fungal ( $A$. fumigatus sakA $\Delta, m p k C \Delta$ ) tolerance to fludioxonil was based on comparison of radial growth between treated and control fungal colonies (See Figure 6). For the above assays, fungal conidia $\left(5 \times 10^{3}\right)$ were diluted in phosphate buffered saline and applied as a drop onto the center of PDA plates containing: (1) No treatment (control); (2) 2H4M (0.1, 0.2, 0.3 , $0.4,0.5,0.6,0.7,0.8,0.9,1.0 \mathrm{mM})$; (3) fludioxonil $(50 \mu \mathrm{M})$; and (4) $2 \mathrm{H} 4 \mathrm{M}+$ fludioxonil. Growth was observed for five to seven days at $35^{\circ} \mathrm{C}$.

\subsubsection{Liquid Bioassay in Filamentous Fungi (CLSI) and S. cerevisiae (EUCAST)}

To determine the precise level of compound interaction between $2 \mathrm{H} 4 \mathrm{M}(0.1,0.2,0.4,0.8,1.6,3.2$, $6.4 \mathrm{mM})$ and monoterpenoid phenols $(0.1,0.2,0.4,0.8,1.6,3.2,6.4 \mathrm{mM})$ in the strains of filamentous fungi (Aspergillus, Penicillium), checkerboard bioassays (triplicate) $\left(0.4 \times 10^{4}-5 \times 10^{4} \mathrm{CFU} / \mathrm{mL}\right.$ ) were performed in microtiter wells using a broth microdilution method (in RPMI 1640 medium; Sigma Co., St. Louis, MO, USA), according to protocols outlined by the Clinical and Laboratory Standards Institute (CLSI) M38-A [44]. RPMI 1640 medium was supplemented with $0.03 \%$ L-glutamine and buffered with $0.165 \mathrm{mM}$ 3-(N-morpholino) propanesulfonic acid (Sigma Co., St. Louis, MO, USA). Minimum Inhibitory Concentrations (MICs), lowest concentration of agents showing no visible fungal growth in microtiter wells ( $200 \mu \mathrm{L}$ per well), were assessed after $48 \mathrm{~h}$. Minimum Fungicidal Concentrations (MFCs), lowest concentration of agents achieving $\geqslant 99.9 \%$ fungal death, were determined following completion of MIC assays by spreading entire volumes of microtiter wells $(200 \mu \mathrm{L})$ onto individual PDA (recovery) plates, and culturing for additional $48 \mathrm{~h}$ (at 28 or $35{ }^{\circ} \mathrm{C}$, depending on types of filamentous fungi). Compound interactions, i.e., Fractional Inhibitory Concentration Indices (FICIs) and Fractional Fungicidal Concentration Indices (FFCI), were calculated as follows: FICI or FFCI $=($ MIC or MFC of compound $\mathrm{A}$ in combination with compound $\mathrm{B} / \mathrm{MIC}$ or MFC of compound $\mathrm{A}$, alone) + (MIC or MFC of compound $\mathrm{B}$ in combination with compound $\mathrm{A} / \mathrm{MIC}$ or MFC of compound $\mathrm{B}$, alone). Levels and types of compound interactions between antifungal agents $(2 \mathrm{H} 4 \mathrm{M}$ and thymol or carvacrol) were defined as: synergistic (FICI or FFCI $\leqslant 0.5$ ) or indifferent (FICI or FFCI $>0.5-4)$ [49].

Compound interaction between $2 \mathrm{H} 4 \mathrm{M}(0.1,0.2,0.4,0.8,1.6,3.2,6.4 \mathrm{mM})$ and thymol or carvacrol $(0.1,0.2,0.4,0.8,1.6,3.2 \mathrm{mM})$ in $S$. cerevisiae was also determined by using checkerboard broth dilution bioassays in microtiter plates (with SG liquid medium; Sigma Co., St. Louis, MO, USA) according to methods outlined by the European Committee on Antimicrobial Susceptibility Testing (EUCAST) [48].

\subsection{Growth Recovery Bioassay for S. cerevisiae bck1 $\Delta$ and slt2 $\Delta$ Mutants}

To examine the effect of antifungal agents (2-Hydroxy-4-methoxybenzaldehyde (2H4M), 2,3-Dimethoxybenzaldehyde (2,3-DMBA), thymol, carvacrol) on cell wall integrity system of fungi, sorbitol recovery bioassays were performed (See [47] for method). Tenfold serially diluted (See "Agar plate bioassays in S. cerevisiae" above) strains of $S$. cerevisiae BY4741, bck1 $\Delta$ and slt2 $\Delta$ were spotted on (1) SG only (No treatment control); (2) SG + caffeine (5.0 mM; Positive control), thymol or carvacrol 
(0.1 0.2, 0.3, 0.4, 0.5 mM), 2H4M (0.1, 0.2, 0.3, 0.4, 0.5, 0.6, 0.7, 0.8, 0.9, 1.0, 1.1, 1.5 mM) or 2,3-DMBA $(0.5,1.0,2.0,3.0,4.0,5.0 \mathrm{mM})$ (viz., Testing sensitivity of $b c k 1 \Delta$ and slt $2 \Delta$ mutants to test compounds); and (3) SG + sorbitol (0.5 M) + caffeine, thymol, carvacrol, 2H4M or 2,3-DMBA (viz., Testing recovery of $b c k 1 \Delta$ and slt $2 \Delta$ mutants, by sorbitol, from sensitivity to antifungal reagents). Cell growth was monitored for 5 to 7 days. If the growth score of $S$. cerevisiae bck $1 \Delta$ and slt $2 \Delta$ on the sorbitol-containing medium was higher than that on the "no sorbitol" medium, the test compounds were considered to affect cell wall integrity system.

\subsection{Aflatoxin Analysis of Fungal Cultures}

Test compounds (thymol, carvacrol, 2H4M), dissolved in distilled water, were filter-sterilized (Millipore Millex GP, Billerica, MA, USA) before incorporation into PDA. Ten mL of PDA containing test compounds (See Table 6 and text for concentrations) were poured into Petri dish $(60 \mathrm{~mm})$ in triplicate for each concentration. Fungal spores of $A$. parasiticus and A. flavus strains, stored on PDA at $30{ }^{\circ} \mathrm{C}$ for 7 days, were collected on a sterile cotton swab and dispersed in $0.05 \%$ Tween 80 solution (Sigma Co., St. Louis, MO, USA). Fungal conidia (200 CFU/5 $\mu \mathrm{L}$ ) from the prepared suspensions were applied as a drop onto the center of PDA plates, and were incubated at $30{ }^{\circ} \mathrm{C}$ for 5 days. The entire culture (agar medium plus fungal mat) was then extracted in $50 \mathrm{~mL}$ methanol (Fisher, Thermo Fisher Scientific, Waltham, MA, USA), and $1 \mathrm{~mL}$ aliquot was filtered through a $0.45 \mu \mathrm{m}$ nylon syringe filter (Pall Acrodisc, Port Washington, NY, USA). An aliquot of $20 \mu \mathrm{L}$ was analyzed for aflatoxins using an Agilent 1100 HPLC system (Santa Clara, CA, USA), which consists of a degasser, autosampler, quaternary pump, fluorescence detector, and a postcolumn photochemical reactor for enhanced detection (PHRED, Aura Industries, New York, NY, USA). Aflatoxins were separated on an Inertsil $4.6 \mathrm{~mm} \times 250 \mathrm{~mm}$ ODS-3 column (GL Sciences, Torrance, CA, USA) using an isocratic mobile phase of water/acetonitrile/methanol (45/25/30) at a flow rate of $1 \mathrm{~mL} / \mathrm{min}$ with fluorescence detection (365 nm excitation, $455 \mathrm{~nm}$ emission). Aflatoxin values were determined using standard curves prepared for each of the individual compounds.

\subsection{Statistical Analysis}

Statistical analysis (student's $t$-test) was performed based on "Statistics to use" [58], where $p<0.05$ was considered significant.

\section{Conclusions}

In this study, levels of compound interactions between monoterpenoid phenols (carvacrol, thymol) and a chemosensitizer (2H4M) were determined for the enhancement of antifungal efficacy. Key features identified for the antifungal or antimycotoxigenic potential of compounds are as follows: (1) Among fifteen benzaldehyde analogs examined, nine compounds inhibited the growth of $b c k 1 \Delta$ and slt2 $\Delta$, the cell wall integrity mutants of $S$. cerevisiae, with structure-activity relationship. 2H4M exhibited the highest antifungal activity among test compounds; (2) $2 \mathrm{H} 4 \mathrm{M}$ possessed a chemosensitizing capability to carvacrol or thymol in yeasts, where chemosensitization enhanced the antimycotic potency of test compounds. The $2 \mathrm{H} 4 \mathrm{M}$, a cell wall perturbing chemosensitizer, and monoterpenoid phenols could affect common cellular targets, i.e., cell wall integrity system of fungi, which results in synergistic inhibition of fungal growth; (3) In yeast chemosensitization, thymol required much lower concentration to achieve complete inhibition of yeast growth compared to carvacrol, thus reflecting structure-activity relationship; (4) In filamentous fungal tests, co-administration of $2 \mathrm{H} 4 \mathrm{M}$ with carvacrol or thymol resulted in the achievement of synergism in Aspergillus and Penicillium strains; (5) Carvacrol or thymol further exacerbated the vulnerability (namely, defects in countering oxidative stress) of the oxidative MAPK mutants (sakA $\Delta, m p k C \Delta$ ) of A. fumigatus; (6) A. fumigatus or A. flavus were more susceptible to thymol compared to carvacrol, while the level of antimycotic activity of carvacrol or thymol was vastly similar in $A$. parasiticus or P. expansum (compound-strain relationship); (7) Co-application of $2 \mathrm{H} 4 \mathrm{M}$ with fludioxonil overcame 
fungal tolerance to fludioxonil, where the cell wall interfering capability of $2 \mathrm{H} 4 \mathrm{M}$ might enhance the susceptibility of the oxidative MAPK mutants (A. fumigatus sakA $\Delta, m p k C \Delta$ ) to fludioxonil, possibly by increased penetration of fludioxonil into the fungal cell through perturbed cell wall; (8) Thymol and carvacrol enhanced aflatoxin production in A. flavus and A. parasiticus. Although 2H4M also potentiated the aflatoxin production in A. flavus, this compound reduced the aflatoxin production in A. parasiticus at all concentrations examined (i.e., strain specificity for the antimycotoxigenic activity of $2 \mathrm{H} 4 \mathrm{M}$ ); (9) Thymol or carvacrol also enhanced the sclerotial differentiation in A. flavus or A. parasiticus, depending on dosages and types of test compounds. A. flavus 3357 produced higher number of sclerotia compared to A. flavus 4212 (w/carvacrol or thymol), while A. parasiticus developed more sclerotia with thymol than with carvacrol. However, sclerotia development was almost not detected with the treatment of $2 \mathrm{H} 4 \mathrm{M}$.

In previous studies in yeasts, another signaling pathway, namely the "intact" oxidative MAPK pathway, was also shown to be important for fungal susceptibility to cell wall perturbing agents [50-53]. Results showed that mutations in the antioxidant system could develop fungal resistance to cell wall disrupting agents. For example, the $S$. cerevisiae oxidative MAPK pathway mutants (e.g., MAPK or MAPK kinase mutants, the upstream transmembrane osmosensor or histidine kinase osmosensor mutants in the same signaling cascade, etc.) exhibited tolerance to the cell wall-perturbing agents, such as calcofluor white [51-53]. Therefore, existence of the "intact" oxidative MAPK pathway of fungi is necessary for effective control of pathogens. Nonetheless, the antioxidant mutants of $A$. fumigatus ( $\operatorname{sak} A \Delta, m p k C \Delta$ ) tested in this study did not develop tolerance to $2 \mathrm{H} 4 \mathrm{M}$ or monoterpenoid phenols, while $2 \mathrm{H} 4 \mathrm{M}$ further overcame fungal tolerance to the phenylpyrrole fungicide fludioxonil.

In conclusion, $2 \mathrm{H} 4 \mathrm{M}$, a natural phenolic compound, possesses a potential to serve as an antimycotic chemosensitizer in combination with monoterpenoid phenols. 2H4M-mediated chemosensitization, as described in this study, can modulate/debilitate the cell wall integrity system of fungal strains, which can lower effective doses of antimycotic agent co-administered. Future studies are needed for comprehensive determination of optimum chemosensitization in various fungal pathogens by including additional cell wall disrupting agents. It would also be interesting to know whether antifungal activity correlates with chemosensitizing activity, or whether a circumstance similar to that for piperazinyl quinolone with fluconazole [32], exists for benzaldehyde analogs with no antifungal activity.

Acknowledgments: This research was conducted under USDA-ARS CRIS Project 5325-42000-037-00D.

Author Contributions: Jong H. Kim designed and performed research including data analysis and interpretation, literature search, and wrote the manuscript. Kathleen L. Chan performed antifungal bioassays and prepared the figures. Noreen Mahoney analyzed aflatoxin production in Aspergillus strains.

Conflicts of Interest: The authors declare no conflict of interest.

\section{References}

1. Denning, D.W. Invasive aspergillosis. Clin. Infect. Dis. 1998, 26, 781-803. [CrossRef] [PubMed]

2. Anderson, M.J.; Brookman, J.L.; Denning, D.W. Aspergillus. In Genomics of Plants and Fungi; Prade, R.A., Bohnert, H.J., Eds.; Marcel Dekker: New York, NY, USA, 2003; pp. 1-39.

3. Marr, K.A.; Patterson, T.; Denning, D. Aspergillosis. Pathogenesis, clinical manifestations, and therapy. Infect. Dis. Clin. N. Am. 2002, 16, 875-894. [CrossRef]

4. Roilides, E.; Holmes, A.; Blake, C.; Pizzo, P.A.; Walsh, T.J. Impairment of neutrophil antifungal activity against hyphae of Aspergillus fumigatus in children infected with human immunodeficiency virus. J. Infect. Dis. 1993, 167, 905-911. [CrossRef] [PubMed]

5. Campbell, B.C.; Molyneux, R.J.; Schatzki, T.F. Current research on reducing pre- and post-harvest aflatoxin contamination of US almond, pistachio and walnut. J. Toxicol. Toxin Rev. 2003, 22, 225-266. [CrossRef]

6. Frizzell, C.; Elliott, C.T.; Connolly, L. Effects of the mycotoxin patulin at the level of nuclear receptor transcriptional activity and steroidogenesis in vitro. Toxicol. Lett. 2014, 229, 366-373. [CrossRef] [PubMed] 
7. Cools, H.J.; Hammond-Kosack, K.E. Exploitation of genomics in fungicide research: Current status and future perspectives. Mol. Plant Pathol. 2013, 14, 197-210. [CrossRef] [PubMed]

8. Possiede, Y.M.; Gabardo, J.; Kava-Cordeiro, V.; Galli-Terasawa, L.V.; Azevedo, J.L.; Glienke, C. Fungicide resistance and genetic variability in plant pathogenic strains of Guignardia citricarpa. Braz. J. Microbiol. 2009, 40, 308-313. [CrossRef] [PubMed]

9. Ellner, F.M. Results of long-term field studies into the effect of strobilurin containing fungicides on the production of mycotoxins in several winter wheat varieties. Mycotoxin Res. 2005, 21, 112-115. [CrossRef] [PubMed]

10. Bayer CropScience. Strobilurin Fungicides Increase DON Levels in Wheat, Reduce Quality. Available online: https://www.bayercropscience.us/ /media/BayerCropScience/Country-United-StatesInternet/Documents/News/2014AgIssues/docs/FusariumHeadBlightFeatureStory.ashx (accessed on 25 August 2015).

11. Markoglou, A.N.; Doukas, E.G.; Malandrakis, A.A. Effect of anilinopyrimidine resistance on aflatoxin production and fitness parameters in Aspergillus parasiticus Speare. Int. J. Food Microbiol. 2011, 146, 130-136. [CrossRef] [PubMed]

12. Doukas, E.G.; Markoglou, A.N.; Vontas, J.G.; Ziogas, B.N. Effect of DMI-resistance mechanisms on cross-resistance patterns, fitness parameters and aflatoxin production in Aspergillus parasiticus Speare. Fungal Genet. Biol. 2012, 49, 792-801. [CrossRef] [PubMed]

13. Markoglou, A.N.; Doukas, E.G.; Ziogas, B.N. Phenylpyrrole-resistance and aflatoxin production in Aspergillus parasiticus Speare. Int. J. Food Microbiol. 2008, 127, 268-275. [CrossRef] [PubMed]

14. Zhang, Y.J.; Yu, J.J.; Zhang, Y.N.; Zhang, X.; Cheng, C.J.; Wang, J.X.; Hollomon, D.W.; Fan, P.S.; Zhou, M.G. Effect of carbendazim resistance on trichothecene production and aggressiveness of Fusarium graminearum. Mol. Plant Microbe Interact. 2009, 22, 1143-1150. [CrossRef] [PubMed]

15. D'Mello, J.P.F.; Macdonald, A.M.C.; Briere, L. Mycotoxin production in a carbendazim-resistant strain of Fusarium sporotrichioides. Mycotoxin Res. 2000, 16, 101-111. [CrossRef] [PubMed]

16. Karaoglanidis, G.S.; Markoglou, A.N.; Bardas, G.A.; Doukas, E.G.; Konstantinou, S.; Kalampokis, J.F. Sensitivity of Penicillium expansum field isolates to tebuconazole, iprodione, fludioxonil and cyprodinil and characterization of fitness parameters and patulin production. Int. J. Food Microbiol. 2011, 145, 195-204. [CrossRef] [PubMed]

17. Malandrakis, A.A.; Markoglou, A.N.; Konstantinou, S.; Doukas, E.G.; Kalampokis, J.F.; Karaoglanidis, G.S. Molecular characterization, fitness and mycotoxin production of benzimidazole-resistant isolates of Penicillium expansum. Int. J. Food Microbiol. 2013, 162, 237-244. [CrossRef] [PubMed]

18. Schmidt-Heydt, M.; Stoll, D.; Geisen, R. Fungicides effectively used for growth inhibition of several fungi could induce mycotoxin biosynthesis in toxigenic species. Int. J. Food Microbiol. 2013, 166, 407-412. [CrossRef] [PubMed]

19. Beauvais, A.; Latgé, J.P. Membrane and cell wall targets in Aspergillus fumigatus. Drug Resist. Updat. 2001, 4, 38-49. [CrossRef] [PubMed]

20. Levin, D.E.; Fields, F.O.; Kunisawa, R.; Bishop, J.M.; Thorner, J. A candidate protein kinase C gene, PKC1, is required for the $S$. cerevisiae cell cycle. Cell 1990, 62, 213-224. [CrossRef]

21. Fuchs, B.B.; Mylonakis, E. Our paths might cross: The role of the fungal cell wall integrity pathway in stress response and cross talk with other stress response pathways. Eukaryot. Cell 2009, 8, 1616-1625. [CrossRef] [PubMed]

22. Fujioka, T.; Mizutani, O.; Furukawa, K.; Sato, N.; Yoshimi, A.; Yamagata, Y.; Nakajima, T.; Abe, K. MpkA-Dependent and -independent cell wall integrity signaling in Aspergillus nidulans. Eukaryot. Cell 2007, 6, 1497-1510. [CrossRef] [PubMed]

23. Perlin, D.S. Mechanisms of echinocandin antifungal drug resistance. Ann. N. Y. Acad. Sci. 2015. [CrossRef] [PubMed]

24. Walker, L.A.; Lee, K.K.; Munro, C.A.; Gow, N.A. Caspofungin treatment of Aspergillus fumigatus results in ChsG-dependent upregulation of chitin synthesis and the formation of chitin-rich micro-colonies. Antimicrob. Agents Chemother. 2015. [CrossRef] [PubMed]

25. Odds, F.C.; Brown, A.J.; Gow, N.A. Antifungal agents: Mechanisms of action. Trends Microbiol. 2003, 11, 272-279. [CrossRef] 
26. Aspergillus Comparative Database. Available online: http://www.broadinstitute.org/annotation/genome/ aspergillus_group/MultiHome.html (accessed on 25 August 2015).

27. Xue, T.; Nguyen, C.K.; Romans, A.; May, G.S. A mitogen-activated protein kinase that senses nitrogen regulates conidial germination and growth in Aspergillus fumigatus. Eukaryot. Cell 2004, 3, 557-560. [CrossRef] [PubMed]

28. Reyes, G.; Romans, A.; Nguyen, C.K.; May, G.S. Novel mitogen-activated protein kinase MpkC of Aspergillus fumigatus is required for utilization of polyalcohol sugars. Eukaryot. Cell 2006, 5, 1934-1940. [CrossRef] [PubMed]

29. Li, H.X.; Xiao, C.L. Characterization of fludioxonil-resistant and pyrimethanil-resistant phenotypes of Penicillium expansum from apple. Phytopathology 2008, 98, 427-435. [CrossRef] [PubMed]

30. Sacharomyces Genome Database. Available online: http://www.yeastgenome.org (accessed on 22 August 2015).

31. Campbell, B.C.; Chan, K.L.; Kim, J.H. Chemosensitization as a means to augment commercial antifungal agents. Front. Microbiol. 2012, 3, 79. [CrossRef] [PubMed]

32. Youngsaye, W.; Hartland, C.L.; Morgan, B.J.; Ting, A.; Nag, P.P.; Vincent, B.; Mosher, C.A.; Bittker, J.A.; Dandapani, S.; Palmer, M.; et al. ML212: A small-molecule probe for investigating fluconazole resistance mechanisms in Candida albicans. Beilstein J. Org. Chem. 2013, 9, 1501-1507. [CrossRef] [PubMed]

33. Keniya, M.V.; Fleischer, E.; Klinger, A.; Cannon, R.D.; Monk, B.C. Inhibitors of the Candida albicans major facilitator superfamily transporter Mdr1p responsible for fluconazole resistance. PLoS ONE 2015, 10, e0126350. [CrossRef] [PubMed]

34. Niimi, K.; Harding, D.R.; Parshot, R.; King, A.; Lun, D.J.; Decottignies, A.; Niimi, M.; Lin, S.; Cannon, R.D.; Goffeau, A.; et al. Chemosensitization of fluconazole resistance in Saccharomyces cerevisiae and pathogenic fungi by a D-octapeptide derivative. Antimicrob. Agents Chemother. 2004, 48, 1256-1271. [CrossRef] [PubMed]

35. Freiesleben, S.H.; Jäger, A.K. Correlation between plant secondary metabolites and their antifungal mechanisms-A review. Med. Aromat. Plants 2014, 3, 154.

36. Beekrum, S.; Govinden, R.; Padayachee, T.; Odhav, B. Naturally occurring phenols: A detoxification strategy for fumonisin B1. Food Addit. Contam. 2003, 20, 490-493. [CrossRef] [PubMed]

37. Guillen, F.; Evans, C.S. Anisaldehyde and veratraldehyde acting as redox cycling agents for $\mathrm{H}_{2} \mathrm{O}_{2}$ production by Pleurotus eryngii. Appl. Environ. Microbiol. 1994, 60, 2811-2817. [PubMed]

38. Jacob, C. A scent of therapy: Pharmacological implications of natural products containing redox-active sulfur atoms. Nat. Prod. Rep. 2006, 23, 851-863. [CrossRef] [PubMed]

39. Rao, A.; Zhang, Y.; Muend, S.; Rao, R. Mechanism of antifungal activity of terpenoid phenols resembles calcium stress and inhibition of the TOR pathway. Antimicrob. Agents Chemother. 2010, 54, 5062-5069. [CrossRef] [PubMed]

40. U.S. Food and Drug Administration (FDA). Everything Added to Food in the United States. Available online: http:/ /www.fda.gov/Food/IngredientsPackagingLabeling/FoodAdditivesIngredients / ucm115326.htm (accessed on 7 August 2015).

41. Bi, X.; Guo, N.; Jin, J.; Liu, J.; Feng, H.; Shi, J.; Xiang, H.; Wu, X.; Dong, J.; Hu, H.; et al. The global gene expression profile of the model fungus Saccharomyces cerevisiae induced by thymol. J. Appl. Microbiol. 2010, 108, 712-722. [CrossRef] [PubMed]

42. Jeong, E.Y.; Cho, K.S.; Lee, H.S. Food protective effects of Periploca sepium oil and its active component against stored food mites. J. Food Prot. 2012, 75, 118-122. [CrossRef] [PubMed]

43. Shi, J.; Yamashita, T.; Todo, A.; Nitoda, T.; Izumi, M.; Baba, N.; Nakajima, S. Repellent from traditional Chinese medicine, Periploca sepium Bunge. Z. Naturforsch. C 2007, 62, 821-825. [CrossRef] [PubMed]

44. Clinical and Laboratory Standards Institute (CLSI). Reference Method for Broth Dilution Antifungal Susceptibility Testing of Filamentous Fungi: Approved Standard-Second Edition. CLSI document M38-A2; Clinical and Laboratory Standards Institute: Wayne, PA, USA, 2008.

45. Reinoso-Martín, C.; Schüller, C.; Schuetzer-Muehlbauer, M.; Kuchler, K. The yeast protein kinase C cell integrity pathway mediates tolerance to the antifungal drug caspofungin through activation of Slt2p mitogen-activated protein kinase signaling. Eukaryot. Cell 2003, 2, 1200-1210. [CrossRef] [PubMed] 
46. Senter, P.D.; Al-Abed, Y.; Metz, C.N.; Benigni, F.; Mitchell, R.A.; Chesney, J.; Han, J.; Gartner, C.G.; Nelson, S.D.; Todaro, G.J.; et al. Inhibition of macrophage migration inhibitory factor (MIF) tautomerase and biological activities by acetaminophen metabolites. Proc. Natl. Acad. Sci. USA 2002, 99, 144-149. [CrossRef] [PubMed]

47. Ferreira, C.; Silva, S.; van Voorst, F.; Aguiar, C.; Kielland-Brandt, M.C.; Brandt, A.; Lucas, C. Absence of Gup1p in Saccharomyces cerevisiae results in defective cell wall composition, assembly, stability and morphology. FEMS Yeast Res. 2006, 6, 1027-1038. [CrossRef] [PubMed]

48. Arendrup, M.C.; Cuenca-Estrella, M.; Lass-Flörl, C.; Hope, W. EUCAST technical note on the EUCAST definitive document EDef 7.2: Method for the determination of broth dilution minimum inhibitory concentrations of antifungal agents for yeasts EDef 7.2 (EUCAST-AFST). Clin. Microbiol. Infect. 2012, 18, E246-E247. [CrossRef] [PubMed]

49. Odds, F.C. Synergy, antagonism, and what the chequerboard puts between them. J. Antimicrob. Chemother. 2003, 52, 1. [CrossRef] [PubMed]

50. Alonso-Monge, R.; Navarro-García, F.; Molero, G.; Diez-Orejas, R.; Gustin, M.; Pla, J.; Sánchez, M.; Nombela, C. Role of the mitogen-activated protein kinase Hog1p in morphogenesis and virulence of Candida albicans. J. Bacteriol. 1999, 181, 3058-3068. [PubMed]

51. García-Rodriguez, L.J.; Durán, A.; Roncero, C. Calcofluor antifungal action depends on chitin and a functional high-osmolarity glycerol response (HOG) pathway: Evidence for a physiological role of the Saccharomyces cerevisiae HOG pathway under noninducing conditions. J. Bacteriol. 2000, 182, 2428-2437. [CrossRef] [PubMed]

52. Jiang, B.; Ram, A.F.; Sheraton, J.; Klis, F.M.; Bussey, H. Regulation of cell wall beta-glucan assembly: PTC1 negatively affects PBS2 action in a pathway that includes modulation of EXG1 transcription. Mol. Gen. Genet. 1995, 248, 260-269. [CrossRef] [PubMed]

53. Lai, M.H.; Silverman, S.J.; Gaughran, J.P.; Kirsch, D.R. Multiple copies of PBS2, MHP1 or LRE1 produce glucanase resistance and other cell wall effects in Saccharomyces cerevisiae. Yeast 1997, 13, 199-213. [CrossRef]

54. Kojima, K.; Takano, Y.; Yoshimi, A.; Tanaka, C.; Kikuchi, T.; Okuno, T. Fungicide activity through activation of a fungal signalling pathway. Mol. Microbiol. 2004, 53, 1785-1796. [CrossRef] [PubMed]

55. Grintzalis, K.; Vernardis, S.I.; Klapa, M.I.; Georgiou, C.D. Role of oxidative stress in sclerotial differentiation and aflatoxin B1 biosynthesis in Aspergillus flavus. Appl. Environ. Microbiol. 2014, 80, 5561-5571. [CrossRef] [PubMed]

56. Valiante, V.; Jain, R.; Heinekamp, T.; Brakhage, A.A. The MpkA MAP kinase module regulates cell wall integrity signaling and pyomelanin formation in Aspergillus fumigatus. Fungal Genet. Biol. 2009, 46, 909-918. [CrossRef] [PubMed]

57. Jain, R.; Valiante, V.; Remme, N.; Docimo, T.; Heinekamp, T.; Hertweck, C.; Gershenzon, J.; Haas, H.; Brakhage, A.A. The MAP kinase MpkA controls cell wall integrity, oxidative stress response, gliotoxin production and iron adaptation in Aspergillus fumigatus. Mol. Microbiol. 2011, 82, 39-53. [CrossRef] [PubMed]

58. Kirkman, T.W. Statistics to Use. Available online: http://www.physics.csbsju.edu/stats/ (accessed on 12 August 2015).

(C) 2015 by the authors; licensee MDPI, Basel, Switzerland. This article is an open access article distributed under the terms and conditions of the Creative Commons by Attribution (CC-BY) license (http://creativecommons.org/licenses/by/4.0/). 